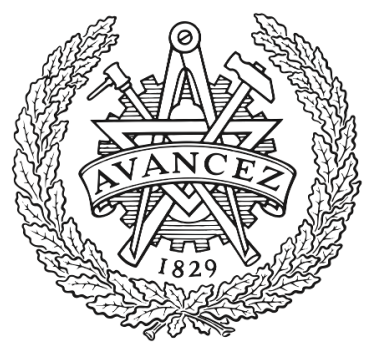

CHALMERS

UNIVERSITY OF TECHNOLOGY

\title{
A framework for operative and social sustainability functionalities in Human- Centric Cyber-Physical Production Systems
}

Downloaded from: https://research.chalmers.se, 2023-04-26 13:07 UTC

Citation for the original published paper (version of record):

Pinzone, M., Albé, F., Orlandelli, D. et al (2020). A framework for operative and social sustainability functionalities in Human- Centric

Cyber-Physical Production Systems. Computers and Industrial Engineering, 139.

http://dx.doi.org/10.1016/j.cie.2018.03.028

N.B. When citing this work, cite the original published paper. 


\section{Accepted Manuscript}

A framework for operative and social sustainability functionalities in HumanCentric Cyber-Physical Production Systems

Marta Pinzone, Ilaria Barletta, Cecilia Berlin, Federico Albè, Davide Orlandelli, Björn Johansson, Marco Taisch

PII: S0360-8352(18)30113-X

DOI: https://doi.org/10.1016/j.cie.2018.03.028

Reference:

CAIE 5132

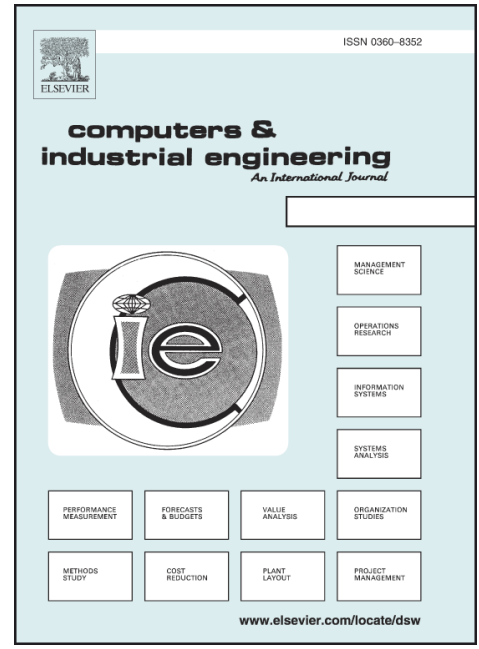

To appear in:

Computers \& Industrial Engineering

Please cite this article as: Pinzone, M., Barletta, I., Berlin, C., Albè, F., Orlandelli, D., Johansson, B., Taisch, M., A framework for operative and social sustainability functionalities in Human-Centric Cyber-Physical Production Systems, Computers \& Industrial Engineering (2018), doi: https://doi.org/10.1016/j.cie.2018.03.028

This is a PDF file of an unedited manuscript that has been accepted for publication. As a service to our customers we are providing this early version of the manuscript. The manuscript will undergo copyediting, typesetting, and review of the resulting proof before it is published in its final form. Please note that during the production process errors may be discovered which could affect the content, and all legal disclaimers that apply to the journal pertain. 
TITLE:

A framework for operative and social sustainability functionalities in Human-Centric CyberPhysical Production Systems

\section{AUTHORS:}

Marta Pinzone (corresponding author), Politecnico di Milano, Department of Management Engineering, Via Lambruschini 4/B, 20156 Milan (Italy) - marta.pinzone@polimi.it

Ilaria Barletta, Chalmers University of Technology, Division of Production Systems, Department of Industrial and Materials Science, Hörsalsvägen 7A, Göteborg (Sweden)

Cecilia Berlin, Chalmers University of Technology, Division of Production Systems, Department of Industrial and Materials Science, Hörsalsvägen 7A, Göteborg (Sweden)

Federico Albè, Associazione Fabbrica Intelligente Lombardia, Via E.Oldofredi 23, 20124 Milan (Italy)

Davide Orlandelli, Business Reply, Via Robert Koch, 1/4, 20152 Milan (Italy)

Björn Johansson, Chalmers University of Technology, Division of Production Systems, Department of Industrial and Materials Science, Hörsalsvägen 7A, Göteborg (Sweden)

Marco Taisch, Politecnico di Milano, Department of Management Engineering, Via Lambruschini 4/B, 20156 Milan (Italy) 


\title{
A framework for operative and social sustainability functionalities in Human-Centric Cyber-Physical Production Systems
}

\begin{abstract}
In a near future where manufacturing companies are faced with the rapid technological developments of Cyber-Physical Systems (CPS) and Industry 4.0, a need arises to consider how this will affect human operators remaining as a vital and important resource in modern production systems. What will the implications of these orchestrated and ubiquitous technologies in production - a concept we call Cyber-Physical Production Systems (CPPS) - be on the health, learning and operative performance of human workers? This paper makes three main contributions to address the question. First, it synthesizes the diverse literature regarding CPS and social sustainability in production systems. Second, it conceptualizes a holistic framework, the CyFL Matrix, and outlines a guideline to analyze how the functionalities of a CPPS relate to operational and social sustainability-related performance impacts at different levels of analysis. Finally, it presents an industrial use case, which the CyFL Matrix and the related guidelines are applied to. In doing so, the study offers first support to researchers and manager of manufacturing companies willing to define suitable operational and social sustainability-related performances for Humancentric Cyber-Physical Production Systems of the future.
\end{abstract}

\section{Keyword}

Cyber-Physical Production System, Functionality, Social Sustainability, Human, Performance, Manufacturing, Industry 4.0

\section{Highlights}

- Six Functionalities of a Human-centric CPPS are illustrated

- Three levels of analysis of CPPS are defined

- The CYFLMatrix aims to identify and organise performances in Human-centric CPPS

- CyFL Matrix is a tool for companies interested in Human-centric CPPS' performances

\section{Introduction}

Manufacturing companies are under strong pressure to radically change the way in which they operate (Lee, Bagheri and H. A. Kao, 2014). As automation and information technologies become more and more advanced, interconnected and pervasive in factories and in the way the external environment is also undergoing rapid development, current manufacturing parlance speaks of a $4^{\text {th }}$ industrial revolution, widely referred to as "Industry 4.0" (Kagermann et al., 2013). "Industry 4.0" is based on smart devices, connectivity and embedded sensors (Kagermann et al., 2013) and is achieved via four disruptions (Baur and Wee, 2015): i) rise in data volumes, computational power, and connectivity; ii) emergence of analytics and business-intelligence capabilities; iii) new forms of human-machine interaction; and iv) improvements in transferring digital instructions to the physical world. 
Industry 4.0 is expected to foster significant changes in how industrial workers perform their jobs (Boston Consulting Group, 2015). However, what this implies for human operators is still not well understood or addressed in a systematic way. In this respect, two main contrasting scenarios have been proposed so far (Hirsch-Kreinsen, 2016). One the one hand, a highly technology-centric scenario with extensive automation of many work processes, in which human activities will be reduced to those tasks that cannot or should not be automated for technical, socio-economic or ethical reasons. In this scenario, automation will control the employees with a deskilling impact (Dworschak and Zaiser, 2014). On the other hand, a human-centric scenario, in which human operators will remain the managing and decision-making authority and the repository of experience, while their role in the working process is upgraded via smart tools and assistance systems (Romero et al. 2016). Operators will receive physical and cognitive support when needed (Romero et al. 2016) and will develop new skills (Dworschak and Zaiser, 2014; Boston Consulting Group. 2015).

In this paper, we focus on Cyber-Physical Systems (CPS) in the manufacturing environment (Lee, Bagheri and H. A. Kao, 2014), which can be conceptually understood as a high-performing fusion of humans, machines and information systems collaborating and linking together the physical and the digital ("cyber") world. CPS hold great potential to revolutionize the performance of production systems by enabling a greater range of functionalities that surpass current paradigms regarding speed, delivery precision, quality, versatility and responsiveness to demands, but may also transform the industrial workforce and their work environment, towards a more Human-Centric and therefore socially sustainable setting (Romero et al., 2016; Longo et al., 2017).

This paper specifically addresses the specific application of interconnected and orchestrated CPS in production systems, which we will refer to as a Cyber-Physical Production System (CPPS). We define a CPPS as combination of highly digitalized technological enablers of both a physical and a software-based nature (i.e. a solution based on technologies associated with Industry 4.0), operating successfully alongside humans to create complex, high-quality products and having a high potential to increase human performance. This new paradigm implies that a new generation of workplaces will arise, where the humans in the system continually interact with and is aided by technologies and information (Romero et al., 2016) in ways that render previous operative performance goals and measures obsolete.

Alongside that issue, considering demographic trends in Europe (Berlin et al., 2013; Richter, Bode and Köper, 2014), manufacturing faces a future where there will be increasing numbers of older workers who may need to stay employed longer, to compensate for a dearth of young talent, caused by lower birth rates in recent decades. This means it will become even more crucial for manufacturing companies to provide an attractive and stimulating workplace to attract, develop and sustain a competitive, healthy and satisfied staff (Berlin et al., 2013; Berlin and Adams, 2017). This is understood to be a key determinant for manufacturing industry's long-term success, as well as for societal flourishing (Fantini et al., 2014).

The capacities that a CPPS may offer, and recent social challenges, mean that manufacturing industry managers must re-think their understanding of what is possible to do, and to aim for the right performances to exploit the maximum potentials of the arising new work environments. The challenge is to align an understanding of the requirements of competitiveness with those that represent long-term sustainability (Garetti and Taisch, 2012). All the aspects of social sustainability in manufacturing, such as work-life balance, physical and psychological wellbeing of the workers, ageing, and diversity, need to be considered (Eijnatten, 2000; Taghavi, Barletta and Berlin, 2015) alongside the desired production 
outcomes, in order to achieve system solutions that make the best of people and technologies (Bettoni et al., 2014). The development of an appropriate performance measurement system, identifying the key dimensions and objectives to be measured and designing the measures themselves, is therefore of paramount importance (Arena et al., 2009; Winroth, Almström and Andersson, 2012; Bengo et al., 2016). However, identifying and measuring social aspects in manufacturing, and determining their interaction with production and operative dimensions, still requires significant improvement (Romero et al., 2015; Peruzzini and Pellicciari, 2017), and will be even more crucial when examining the potential benefits of implementing a CPPS (Romero et al., 2016; Gregori et al., 2017).

Therefore, this paper targets three main objectives:

- To synthesize the diverse literature regarding CPS and social sustainability in production systems.

- To define the main functionalities enabled by a CPPS, developing a framework for both industrial and research stakeholders, which helps them navigate the complexity of CPPS.

- To propose a framework that properly describes how the adoption of CPPS impacts on human and the overall system performances. This is done by combining the defined functionalities with a systematic view of a CPPS, as derived from literature. The framework suggests how managers and researchers can structure their understanding of performance impacts stemming from a CPPS and is targeted at helping to define suitable performances to measure in improvement projects or research endeavours.

This paper thereby contributes to the body of knowledge on conceptualizing, understanding and controlling human-centric and socially sustainable CPPS, based on the idea that the realization of a highly digitalized future manufacturing, where social sustainability aspects are managed proactively, has high potential to create value for industry, individuals and society.

The paper is organised as follows: Section 2 illustrates the research method to carry out the study; Section 3 outlines the main findings of the literature review; Section 4 presents the developed framework (i.e., the CyFL Matrix), its main axes (i.e., the CPPS Functionalities and the CPPS level of analysis) and the guidelines to fill it in; Section 5 describes the industrial use case which the framework was applied to; Section 6 discusses the contributions of the study, illustrates the limitations, suggests directions for future research and draws the conclusions.

\section{Research Method}

To achieve the above-mentioned research objectives, first the study included a narrative literature review "to provide the reader with a comprehensive background for understanding current knowledge and highlighting the significance of new research" (Cronin et al., 2008, p. 39). Subsequently, the review findings were synthesized into a framework to illustrate the performance impacts of a socially sustainable CPPS at different levels. This framework was then subjected to an expert evaluation to provide validation and questioning of the framework for continued development. The framework was then applied to a sharp use case in the manufacturing industry. The different steps of the research process are elaborated below:

1. Literature study followed by an open, inductive coding of the sources.

2. The first round of codes were grouped together under higher-order aggregate codes based on the similarity of their objective and intended outcome, both regarding social sustainability and operational performances. 
3. The higher-level codes were discussed among the authors, revised and eventually aggregated into what we have called "functionalities".

4. The functionalities were validated by means of a series of semi-structured interviews with seven academic experts in the fields of CPPS and Sustainability in manufacturing (Table 1), to assess whether they were relevant, comprehensive and made sense to other expert scholars. Each interview lasted one hour and was recorded by the authors.

5. Final synthesis of the operational framework, post-expert evaluation.

6. The framework was tested in a sharp industrial use case.

\subsection{Literature study}

The literature review scope was set to include aspects of social sustainability (with specific reference to human operators in production industry), industrial performance measurements, and advanced automation solutions - specifically the type known as cyber-physical systems - all within the scope of production systems in the manufacturing sector. Because of the novelty and multidisciplinarity of the topic, it was necessary to consider contributions from different bodies of knowledge.

The Scopus online scientific database was searched; we used inclusion in the database as a hallmark for sources being reputable and scientifically trustworthy. The search for publications was conducted as a structured keyword search (either in the title, abstract, or list of keywords) combining keywords related to CPPS, human-centric manufacturing and performance measurement, and the list evolved as new keywords were found in the literature. Table 1 shows the keywords (with permutations for upper- and lowercase as well as plural and singular form) that were used.

Table 1: Keywords used in the literature study

Cyber physical systems

Industrial Data Mining

Scheduling

Manufacturing Key Performance Indicators (KPIs)

Robotics

Internet of Things

Manufacturing Automation

Automatic Setup

Performance management

Manufacturing performance
Ergonomics

Wellbeing

Safety risk

Knowledge Management

Work-Life Balance

Learning

Training

Human-Automation Interaction

Social Sustainability

Papers written in English and published in peer-reviewed journals and conference proceedings from 1981 to 2017 were considered.

After article retrieval, two of the authors performed a first screening and selection by reviewing the content of the abstracts. Identified contributions were included or excluded from the analysis based on their pertinence to the scope of the present study. Subsequently, a snowball search was performed by examining the cited and citing articles of the papers contained in the sample obtained in the previous step. Some older sources have been included for overall historical reference or to provide the seminal reference to e.g. standards and specific terms, but the emphasis on CPS literature has been placed on the last ten years to acknowledge the rapid progress in that field as of late. 
Finally, to understand the contemporary knowledge space, documents from "grey literature" (i.e. either unpublished or published in non-commercial form; International Conferences on Grey Literature, 2004) were also considered. Specifically, international standards related to automation (e.g., ANSI/ISA-95) and enterprise-control systems (e.g., IEC 62264) were surveyed, as well as reference models for Industry 4.0 (e.g., RAMI 4.0). Furthermore, contemporary European and national projects related to CPS (e.g., sCorPiuS, BEinCPPS, DIG IN, 5GEM, Pathfinder) and social sustainability in manufacturing (e.g., Operator of the Future, SO SMART, MAN-MADE) were reviewed, to gain insight into preliminary novel developments and findings not yet published in academic journals.

\subsection{Coding Process}

The selected documents underwent an inductive qualitative coding process to help define how CPPS functionalities can enhance performances that contribute to a socially sustainable, human-centric industrial workplace. An inductive approach is efficient and appropriate when "there is not enough former knowledge about the phenomenon or if this knowledge is fragmented" (Elo and Kyngäs, $2008 \mathrm{p}$. 109). In inductive content analysis, "categories are derived from the material under examination itself, employing an iterative process of category building, testing and revising by constantly comparing categories and data" (Seuring and Gold, 2012 p. 546).

\subsection{Expert Evaluation}

Once the literature study was synthesized into a first framework of CPPS functionalities for enhancing performances to achieve socially sustainable production (called the CyFL Matrix), a series of interviews were performed with experts to assess the relevance, applicability and acceptance of the framework.

We recruited experts among scholars performing research on new production systems and/or social sustainability from different perspectives (ranging from industrial engineering and CPS, to sustainable work systems and organizational design), with various seniority levels (from PhD level to Senior profiles with more than 20 years of experience) and coming from different countries ( 1 from Mexico, 1 from Germany, 2 from Sweden, 3 from Italy). Table 2 provides an overview of the experts.

Table 2: Experts interviewed in the validation process

\begin{tabular}{|l|l|l|}
\hline & Expert & Field of expertise \\
\hline 1 & $\begin{array}{l}\text { Senior Research Scientist and Scientific Project } \\
\text { Manager }\end{array}$ & $\begin{array}{l}\text { Cyber-Physical Human-Centric Production } \\
\text { Systems }\end{array}$ \\
\hline 2 & Senior Researcher at Department of Psychology & Sustainable Work Systems \\
\hline 3 & $\begin{array}{l}\text { Associate Professor at Mechanical Engineering and } \\
\text { Industrial Systems Department }\end{array}$ & Sustainable Manufacturing \\
\hline 4 & $\begin{array}{l}\text { Research coordinator at Management, Economics } \\
\text { and Industrial Engineering Department }\end{array}$ & Socially Sustainable Manufacturing \\
\hline 5 & $\begin{array}{l}\text { Researcher in a H2020 project on CPS in } \\
\text { manufacturing }\end{array}$ & Cyber-Physical Systems in Manufacturing \\
\hline 6 & $\begin{array}{l}\text { PhD Candidate at Department of Product and } \\
\text { Production System Development }\end{array}$ & Human and Automation Optimization \\
\hline 7 & Professor at Business School changes in \\
\hline
\end{tabular}

Inputs from the expert interviews were used to adjust and refine the framework before the next phase. 


\subsection{Use case}

The framework was finally tested in a sharp industrial use case in manufacturing industry, to demonstrate and test the applicability of the proposed tool in addressing real world situations. The chosen case company was an Italian production site of Whirlpool EMEA, which provided a project that the framework was applied to in order to identify how the introduction of CPPS could impact operational and social sustainability performances, and via which performance-enhancing functionalities.

\section{Literature review results}

The literature final data set was composed of 160 documents that yielded three distinct themes: i) social sustainability, ii) performance measurement and iii) CPPS. The scope is illustrated in Figure 1 and the main themes are described below in that order, since the first step of the realization of human-centric, socially sustainable CPPS is to understand what social sustainability is. Then, we describe how to measure it in manufacturing, and finally we elaborate the relevant enabling technologies and structure of CPPS. Together they form the theoretical basis for the structure and content of the subsequent framework formulation (i.e., the CyFL Matrix).

--- Please insert Figure 1: Scope of the literature review, where the manufacturing application area constitutes the chief boundary for inclusion. The three main themes and their found overlaps are indicated.

\subsection{Social Sustainability in production systems}

The paradigm of sustainable development has broadened in scope and has evolved to be a key manufacturing decision attribute (Chen et al., 2015, Fiasché et al., 2016). Concepts like "Socially Sustainable work systems" (Eijnatten, 2000), "Socially Sustainable work places" (Hancock et al., 2015), "Human-centric Factory" (May et al., 2015), "Anthropocentric Cyber Physical Systems" (Pirvu, Zamfirescu and Gorecky, 2014), and similar have all been developed in recent years. More explicitly, achieving a socially sustainable manufacturing work system means that "[...] it should be able to meet the needs of both current and future employees. To that end, it should be able to attract different societal groups as potential workers, i.e. younger, elderly, women, disabled and in general support greater diversity" (Taghavi, Adams and Berlin, 2014 p.585), and in it, operators are free "[...] to choose at any stage in life between different forms of work (work arrangements, field of work) or lifestyles, while being at all times entitled to individual social security" (Hancock et al., 2015).

Social sustainability-driven approaches for manufacturing can be practically substantiated into four identified main areas: Safety management; Ergonomics and human factors; Learning and training; and Work-Life Balance. Table 3 provides an overview of literary sources that elaborate these.

Table 3: Main areas of Social Sustainability

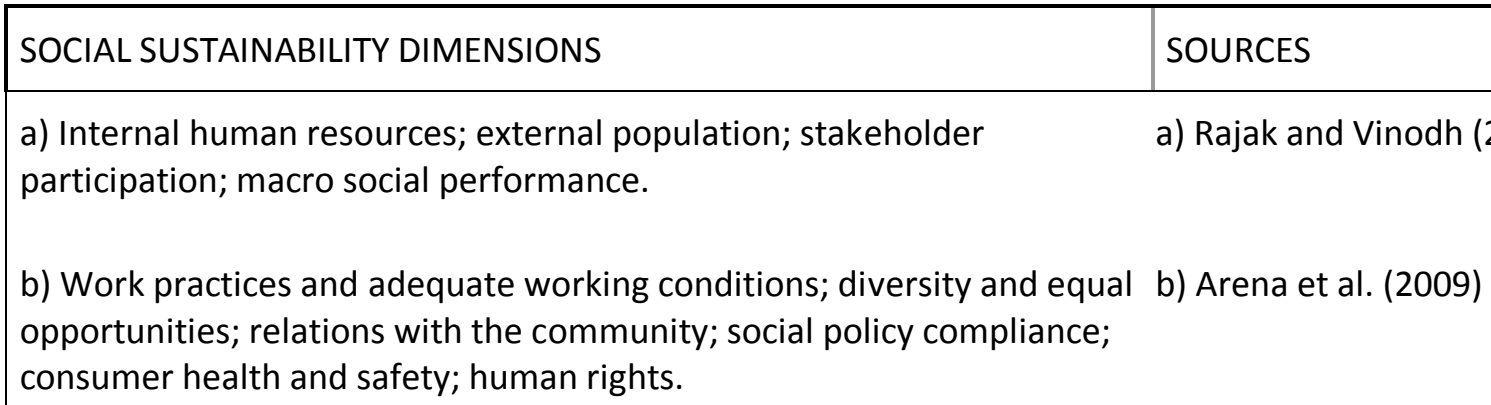


c) Ensuring career and employment security; maintaining and

c) Bettoni et al. (2014) promoting the health and wellbeing of workers; developing skills and competences; reconciling working and non-working life.

FOUR MAIN SOCIAL SUSTAINABILITY AREAS

Safety Management

a) Operational risk

b) Tools for safety management; e.g. probabilistic risk assessment, FN curves, Hazard Analysis, Failure Mode Effect Analysis (FMEA)

a) Physical dimensions - Musculo-Skeletal Disorders (MSDs) ${ }^{1}$; connection to quality and financial aspects ${ }^{1}$; Cumulative Trauma Disorders (CTD $)^{2}$

b) Psychological dimensions - Mental work vs. workload ${ }^{1}$; Measurement methods aided by sensors and data analytics ${ }^{2}$; questionnaires and rating scales to measure individual subjective perception of workload
Ergonomics/Human Factors

SOURCES

(Baldock et al., 2006)

a) Lewis (2003); MIL-STD-882

(2000)

b) MIL-STD-882 (2000); Parry and Winter (1981); Taylor (1994)

Fernandez and Marley (1998); Pretorius and Cilliers (2007).

a) Falck (2009) ${ }^{1}$; Fernandez and Goodman, $(2000)^{2}$

b) Pretorius and Cilliers (2007); Hancock and Chignell (1986) ${ }^{1}$; Wilson and Russell (2003) ${ }^{2}$ $(2007)^{2}$; Dey and Mann $(2010)^{2}$; Fujita, Kato and Tamio (2010) ${ }^{2}$; Meshkati et al. $(1995)^{3}$; Mattson $(2013)^{3}$

Learning and Training

a) Knowledge management - focused on machine OR the human ${ }^{1}$, has great impact on manufacturing performances ${ }^{2}$

b) Training ${ }^{1}$ - Time dedicated ${ }^{2}$; Competitive advantage ("economies of learning" $)^{3}$; Lack of training and disuse of knowledge leads to skill decay $^{4}$

c) Automation in training- Unexpected effects and redefinitions of jobs and tasks

d) Four classes of learning functions that automation can be applied to: information acquisition, information analysis, decision and action selection, and action implementation

e) Virtual and automatic training tools - Intelligent Training Systems $(\text { ITS })^{1}$; importance of prior education ${ }^{2}$ a) Malhotra $(2001)^{1}$, Tan and Wong (2015) $)^{2}$

b) Pinzone et al. $(2016)^{1}$, Krajnc and Glavic (2003) Winroth, Almström and Andersson (2012) ${ }^{2}$; Joung et al. $(2013)^{2}$; Taghavi, Adams and Berlin (2014) ${ }^{2}$; Searcy, Dixon and Neumann (2016) ${ }^{2}$; Adler and Clark (1991) ${ }^{3}$; Rose $(1989)^{4}$

c) Parasuraman and Riley (1997)

d) Parasuraman, Sheridan and Wickens (2000)

e) Kulik and Fletcher (2015) ${ }^{1}$, Greer and Mark (2015) ${ }^{1}$, Rastegarmoghadam and Ziarati (2016) ${ }^{1}$; Amador, Nicolás and Vila (2008) ${ }^{2}$ 
Work-life Balance

a) Definitions and dimensions - integration of the worker's activities, as a worker, into life as a whole ${ }^{1}$; freedom to choose work and work

forms $^{2}$; Socially Sustainable Workplace ${ }^{3}$; Four dimensions; Abilities of a socially sustainable work system;

b) Link between work flexibility, well-being of the operator and improved work-life balance ${ }^{1}$; Smart working ${ }^{2}$; worker involvement and satisfaction with flexibility arrangements ${ }^{3}$ a) Fantini et al. (2014) ${ }^{1}$; Berlin et al. ( 2015) ${ }^{1}$; Hancock et al. $(2015)^{2,3} ; \operatorname{LCSP}(1998)^{3}$; Bettoni et al. (2014) ${ }^{4}$; Taghavi, Adams and Berlin (2014) $)^{5}$; b) Golden et al. (2010) ${ }^{1}$, Golden, Henly and Lambert $(2012)^{1}$; Kim and Oh $(2015)^{2}$; Askenazy $(2004)^{3}$, Lambert $(2008)^{3}$

Safety management has become fundamental in manufacturing practices, generating policy innovations and creating compliance-related processes within companies (Baldock et al., 2006). It targets prediction of how production processes might lose their operational continuity due to events like accidental failures, and evaluation of cost impacts regarding security, environment, operations and production (Woodhouse, 1991; Brown, Willis and Prussia, 2000). The aim of all safety management tools is to assess and manage operational risks (defined as "a pre-identified combination of a probable, unwanted event and its double-folded negative outcome on internal and external stakeholders" by MIL-STD-882, 2000), prevent accidents and protect operators and equipment from possible damage. Hazard Analysis, probabilistic risk assessment and FN curves and Failure Mode Effect Analysis (FMEA) are all well-known examples of such tools. These kinds of preventive approaches result in a more secure workplace environment (which benefits enterprise reputation and compliance) where availability of the system's assets increases, while the costs generated by unexpected events decrease.

Ergonomics (a.k.a. Human Factors) is defined as "the study of the design of a workplace, equipment, machine, tool, product, environment, and system which takes into consideration the human being's physical, physiological, biomechanical, and psychological capabilities and optimizes the effectiveness and productivity of work systems while assuring the safety, health, and well-being of the workers" (Fernandez and Marley, 1998 p. 20). The physiological and biomechanical dimensions are currently the measurable part of ergonomics (Pretorius and Cilliers, 2007). Physical stress in the form of musculoskeletal disorders (MSDs) constitute a great financial burden (in terms of sick leave days) and are commonly targeted with ergonomics interventions; the most important contribution of ergonomics on physical operator health is the reduction of cumulative trauma disorders (CTDs), which cause both work absenteeism (when the worker cannot go to work due to health problems), and work presenteeism (when the worker goes to work but cannot perform the job at the desired speed or quality level). CTDs affect both quality and productivity of the system negatively (Falck, 2009). Most ergonomic risk assessment methods assign a diagnostic risk level to the tasks and related movements that the operator performs, and try to provide decision support to redesign tasks or limit the time in which operators high-risk tarks (Falck, 2009). Psychological stress (or strain) is a dimension that is harder to measure, but is nonetheless significant. Even though a universally accepted concept of mental workload is missing, attempts to model it have been made (e.g. Hancock and Chignell, 1986). Schütte (2007) made an extensive review of the literature on measuring psychological strain and identified two major branches: 1) approaches developed in engineering, referring to the technical performance of work or work functions, and 2) psychological approaches concentrating on the interactions between the employee and his/her work. Some research 
uses physiological parameters to record the intensity and time duration of psychological strain (see $b^{2}$ sources in Table 2), and yet others use questionnaires and rating scales to document the individual's subjective perception of mood, fatigue, effort etc. (see $b^{3}$ sources in Table 2 ).

Learning and training are carried out to allow operators to learn new tasks, concepts and methodologies. From the human-centric production perspective, knowledge is one of the most valuable resources for companies, and managing knowledge means providing and supporting means to raise the knowledge level of the whole socio-technical system. The impact of automation on human training within production is an established research stream, which highlights the sometimes unexpected effects automation can have on tasks and jobs. The necessity to enhance the learning capabilities of operators through organization is also stressed, to overcome the quick change of job tasks and to be able to adapt an aging workforce to the jobs of the future. Four classes of learning functions have been suggested by Parasuraman, Sheridan and Wickens (2000; see Table 2) as system aspects that are possible to automate. Other studies have explored the relevance of using virtual and automatic training tools in learning activities has been explored by different studies, e.g. how Intelligent Tutoring Systems (ITS) positively affect the learning outcomes of test subjects (see Table 2). However, automatic learning systems cannot solve all problems: the level of prior education "is relevant since competence provides the necessary foundation for learning. (...) It is very important to have a match between competence and the skill required to complete the work task" (Amador, Nicolás and Vila, 2008).

Work-Life Balance, understood as the integration of the worker's activities into life as a whole (Fantini et al., 2014; Berlin et al., 2015), is frequently named in the social sustainability as an enabler of socially sustainable work. Characteristics related to the production processes may impose constraints when accommodating the worker's personal requirements (e.g. schedule and workplace flexibility, machine productivity, autonomy and accountability, teamwork, management by objectives, etc.). Another important aspect is the freedom, from the worker perspective, "to choose at any stage in life between different forms of work (...) or lifestyles, while being at all times entitled to individual social security" (Hancock et al., 2015). However, some researchers focus on linking work characteristics and work-life balance, the well-being of the operator (e.g. Golden et al., 2010; Golden, Henly and Lambert, 2012). These findings highlight that offering time flexibility to operators in the workplace, to improve the worklife balance and the general satisfaction with the working environment. Considerations may include flexible working contracts and the more general concept of smart working, i.e. organization of the work that allows work at any time of the day according to a worker's needs (Kim and Oh, 2015).

Based on the definition of Socially Sustainable Workplace by Hancock et al. (2015), the four dimensions mentioned by Bettoni et al. (2014), the abilities described by Taghavi, Adams and Berlin (2014) and the definition by LCSP (1998) (i.e., "the creation of goods and services using processes and systems [...] safe and healthful for employees, communities and consumers; and socially and creatively rewarding for all working people"), we can synthesize some pillars regarding social sustainability for workers. First, working activities should be designed to meet the requirements of all worker life-stages, meaning that the physical and physiological wellbeing of the worker is central. Secondly, the ability to fit the working life to the other life requirements, and not the other way around, is key. This can only be possible if mobility of workplaces is achieved. This can be enabled by the possibility of learning new skills rapidly, and by having working systems that are able to integrate and easily release new resources. A corollary impact on industrial needs is the need for more flexible human resources (in terms of capabilities and requirements) to enable more flexible production systems. Third, while the human resource is working, 
he/she should be motivated as well. This will also impact production and the work environment, regarding performance on an individual and group level.

\subsection{Performance Measurement}

To compete in continuously changing environments, manufacturing companies need to monitor and understand performances. Operational performance measures have traditionally been related to the four main classes of competitive manufacturing priorities: cost, time, quality and flexibility (De Toni and Tonchia, 2001; Neely et al., 1995; Boyer and Lewis 2002).

Cost performance refers to the amount of resources used to produce a product, or supply a service. A particularly important cost-related aspect is linked to productivity (a ratio between output and input) and efficiency (the ratio between productivity and a standard) (Tonchia and Quagini, 2010). The literature offers both total measures (calculated considering all the resources) and specific measures (referring to a single input typology) of productivity and efficiency. Time performance is usually related to fast deliveries, meeting delivery promises and reducing production lead time (Boyer and Lewis, 2002). Quality is defined as "the degree to which a set of inherent characteristics of an object fulfils requirements" (ISO 9000: 2015). In the literature, there appears to be a broad range of quality-related performances used by manufacturing companies, grouped into i) Internal Quality, which refers to the quality of the production processes, in particular their reliability in producing a stable and standard output; and ii) External Quality, which incorporates the dimensions of quality-in-use and customer value and satisfaction (Fynes and Voss, 2001). This performance dimension is usually measured based on the perceived quality by the customers. Flexibility is also regarded to be a multidimensional concept (Ajai et al., 2013), related to reaction to changes in product and in product mix, modifications to designs, fluctuations in materials, changes in sequence or routing of manufacture.

Alongside operational performances, sustainability has risen to a more critical role in the last years, and therefore researchers suggest that environmental and social sustainability should be included among manufacturing competitive priorities (de Burgos Jimenez and Lorente, 2001; Longoni and Cagliano, 2015) and as KPIs in performance measuring systems (Arena et al., 2015). In particular, social sustainability performances refer to societal impacts of manufacturing processes and manufactured products. According to Longoni et al. (2014), social sustainability performances can be classified into internal social sustainability, i.e. the impact that the company has on its workforce; and external social sustainability, i.e. the company's impact on surrounding communities.

To date, social sustainability performances have been mainly addressed more at the corporate level than at operations and plant-level (Winroth et al., 2016), At the corporate level, the Global Reporting Initiative (GRI) framework has become a de facto international standard of sustainability reporting, because it is comprehensive and applicable to all kind of firms (Taghavi et al., 2014). On the other hand, there is no unique reference framework acknowledged in the literature at operations and plant-level (Searcy et al., 2016). Considering just social sustainability indicators from GRI, Taghavi et al. (2014) identified two main areas that are relevant for manufacturing companies at factory level in developed countries: "Labor practices \& decent work" and "Local communities". Similarly, other studies highlighted that three areas are mostly addressed with respect to factory workforce (e.g., NIST, 2011; Joung et al., 2013): i) health and safety of employees, ii) satisfaction within the organization and iii) professional development.

The Health and safety (H\&S) area deals with all aspects of health and safety in the workplace and has a strong focus on the identification of relevant risks and prevention of hazards. More holistic approaches 
that focus on employees' wellbeing, concerning both the physical and psychological strains that an operator has to bear because of his/her working tasks, are emerging (Darr and Johns, 2008; Gerr et al., 2014).

Job satisfaction is defined as the degree to which people like or dislike their jobs and the characteristics of their tasks (Aouadni and Rebai, 2016) and is commonly used as a proxy variable for quality of work. High level of satisfaction leads to low employee absenteeism and turnover, as well as improved task performance and increase in extra-role behaviors that benefit the company.

Concerning professional development, operator learning focuses on the skill acquisition process of single individuals, while human capital is the collective value of employees' competences, resulting from the knowledge, skills acquired by the company's employees (Goldin, 2016). Knowledge and information capital is another important asset of an organization, which represents the quantity and quality of knowledge owned by a manufacturing company (Wong et al., 2015).

The overall result of the organizational efforts on social sustainability can be reflected in the level of attractiveness of the workplace, which is how much potential operators perceive the production system as attractive (Zamfirescu et al., 2014). Table 4 summarizes performance areas that are relevant for CPPS as identified from the literature.

Table 4: Performance areas reviewed

\begin{tabular}{|c|c|c|}
\hline CATEGORY & PERFORMANCE AREA & SOURCES \\
\hline Social Sustainability & $\begin{array}{l}\text { a) Health and safety risk } \\
\text { b) Operators' learning } \\
\text { c) Human Capital } \\
\text { d) Knowledge and Information } \\
\text { Capital } \\
\text { e) Innovation \& Knowledge } \\
\text { f) Employee Satisfaction } \\
\text { g) Wellbeing (Physical) } \\
\text { and Psychological) } \\
\text { h) Attractiveness of Workplace }\end{array}$ & $\begin{array}{l}\text { a) Doran and Van der Graaf, (1996); Krajnc } \\
\text { and Glavic (2003); NIST (2011); Joung et al., } \\
\text { (2012) } \\
\text { b) Anzanello and Fogliatto, (2011); Hewitt et } \\
\text { al. (1992); Jaber, Kher and Davis (2003) } \\
\text { c) Goldin (2016) } \\
\text { d) Tan and Wong (2015) } \\
\text { e) Kim and Oh (2015) } \\
\text { f) Aouadni et al. (2014); Aouadni and Rebai } \\
\text { (2016); Joung et al., (2012); NIST (2011) } \\
\text { g) Darr and Johns (2008); Gerr et al. (2014); } \\
\text { Joung et al., (2012) } \\
\text { h) Zamfirescu et al. (2014) }\end{array}$ \\
\hline Cost & $\begin{array}{l}\text { a) Resource efficiency } \\
\text { b) Cost Efficiency } \\
\text { c) Maintenance costs } \\
\text { d) WIP Level } \\
\text { e) Inventory Costs }\end{array}$ & $\begin{array}{l}\text { a) Boyer and Lewis (2002); Romero and } \\
\text { Noran (2015); Tonchia and Quagini (2010) } \\
\text { b) Boyer and Lewis (2002); Ferdows and De } \\
\text { Meyer (1990): Tonchia and Quagini (2010) } \\
\text { c) Susto et al. (2015) } \\
\text { d) Lin and Lee (2001); Lin, Shie and Tsai }\end{array}$ \\
\hline
\end{tabular}




\begin{tabular}{|c|c|c|}
\hline & & $\begin{array}{l}\text { (2009) } \\
\text { e) Bayindir, Birbil and Frenk (2007); Boyer } \\
\text { and Lewis (2002) }\end{array}$ \\
\hline Quality & $\begin{array}{l}\text { a) Internal Quality } \\
\text { b) External Quality } \\
\text { c) Human Error incidence } \\
\text { d) Communication Quality } \\
\text { e) Operational Risk }\end{array}$ & $\begin{array}{l}\text { a) Rosu et al. (2008); } \\
\text { b) Fynes and Voss (2001); } \\
\text { c) Doran and Van der Graaf (1996); Stottler } \\
\text { and Panichas (2006); Falck (2009); Ramos, } \\
\text { Frasson and Ramachandran (2009); } \\
\text { d) Parasuraman, Sheridan and Wickens } \\
\text { (2000); Pirvu, Zamfirescu and Gorecky, } \\
\text { (2014); VINNOVA, S2 and UDI (2015); Sato } \\
\text { (2014) } \\
\text { e) Lewis (2003) }\end{array}$ \\
\hline Time & $\begin{array}{l}\text { a) Availability } \\
\text { b) Failure modes occurrence } \\
\text { and impact } \\
\text { c) Throughput time / Volume } \\
\text { d) Time efficiency }\end{array}$ & $\begin{array}{l}\text { a) Evans (1997) } \\
\text { b) Muller et al. (2011) } \\
\text { c) Raddon and Grigsby (1997) } \\
\text { d) Boyer and Lewis (2002); El Mola and } \\
\text { Parsaei (2010); May et al. (2015); Konopka } \\
\text { and Trybula (1996) }\end{array}$ \\
\hline Flexibility & $\begin{array}{l}\text { a) Operators' training level } \\
\text { b) Labour Flexibility } \\
\text { c) Traceability (Product) } \\
\text { d) Plant Accessibility } \\
\text { e) Product Flexibility } \\
\text { f) Process Flexibility } \\
\text { g) Production Flexibility } \\
\text { h) Volume flexibility } \\
\text { i) Mix Flexibility } \\
\text { j) Operation Flexibility } \\
\text { k) Expansion Flexibility } \\
\text { l) Market Flexibility } \\
\text { m) Adaptability to a diverse }\end{array}$ & $\begin{array}{l}\text { a) Mavrikios et al. (2013) } \\
\text { b) Ajai et al. (2013) } \\
\text { c) Zaeh and Ostgathe (2009); Harun, Cheng } \\
\text { and Wibbelmann (2008) } \\
\text { d) Lee, Shin and Higa (2007) } \\
\text { e) Ajai et al. (2013) } \\
\text { f) Ajai et al. (2013) } \\
\text { g) Sethi and Sethi (1990); Ajai et al. (2013) } \\
\text { h) Ajai et al. (2013) } \\
\text { j) Neves et al. (2014) } \\
\text { k) Koste and Malhotra (1999) ; Ajai et al. } \\
\text { (2013) } \\
\text { l) Stecke and Raman (1995); Kaplan and } \\
\text { Norton (2000) }\end{array}$ \\
\hline
\end{tabular}




\begin{tabular}{|l|l|l|}
\hline workforce & m) May et al. (2015) \\
$\begin{array}{l}\text { n) Resilience of production } \\
\text { system }\end{array}$ & n) Zhang and Van Luttervelt, (2011) \\
o) Scheduling Robustness & o) Terzi and Cavalieri (2004) \\
p) Routing flexibility & p) Ajai et al. (2013) \\
q) Frozen period & q) Herrera et al. (2015); Geiger and Reinhart \\
(2016)
\end{tabular}

\subsection{Industrial Automation: Cyber-Physical Production Systems}

Industry 4.0 comprises a heterogeneity of ideas and technologies, which needs to be understood by managers of manufacturing companies in order for it to happen in production environments. The technologies introduced into production systems that include human workers as resources should serve to increase the overall system performance, while enabling and facilitating the work efficiency and wellbeing of those human workers. Strategic initiatives like Industry $4.0^{1}$ (Kagermann, Wahlster and Helbig, 2013) and Factories of the Future Roadmap 2020 (Effra, 2013) suggest that the common ground of this revolution is the development of CPPS.

Having a well-designed and maintained system of Information and Communication Technologies (ICT) in factories is pivotal to make right information reach the right person/machine/device at the right time. Different international standards exist to help engineers implement automation solutions. The most renowned is the automation pyramid (Sauter et al., 2011), which for industrial applications evolved into IEC 62264 and then the ISA-95 standard. This is an enterprise standard that introduces a hierarchy, a functional data flow, and an object model for manufacturing systems. The model comprises three types of hierarchies: scheduling and control, equipment, and decision (ANSI-ISA, 2000) and consists of five levels ( 0 to 4 ) that represent in which part of the enterprise a certain part of information is treated. The model's lower levels, 0-2, comprise sensors and programmable logic devices (PLCs) that monitor and control the actual production processes. Different standards, such as ISA-88 (or IEC 61512) and ISO 22400 , are strongly related to the ISA-95, and focus on physical processes for batch production, procedural control models (ISA-88) and performance management (ISO 22400) (ANSI-ISA, 2000).

Today, the application of new digital technologies in manufacturing industry enables a new era. The main digital technologies can be categorized in many ways, e.g. Service Oriented Architectures (SOA) (e.g. Fumagalli et al., 2014), Agent Platforms (e.g. Shen et al., 2006), and Distributed real time control (e.g. Lee, 2008). Those technologies are used as a base to develop ICT-driven paradigms like Cloud Computing, CPS and Internet of Things (IOT). It follows that the traditional automation pyramid will lose its rigid hierarchies, and become flatter.

The standard IEC 61499 has been developed to migrate this rigid hierarchy to a more flexible interaction strategy (Ivanova et al., 2009; Dai, Dubinin and Vyatkin, 2014) known as distributed control systems. It provides a functional model that allows the integration of physical assets and related sensors, actuators and PLC/CN, within flexible and orchestrated production subsystems.

\footnotetext{
${ }^{1}$ In most European literature the term may also be spelled "Industrie 4.0", as the concept originates from Germany.
} 
RAMI 4.0 is the reference architectural model introduced by "the Plattform Industrie 4.0 " to define the scope of each software application developed in the context of Industry 4.0 (Hankel, 2015). The framework combines existing standards and aligns them to Industry 4.0 using three dimensions: hierarchy, architecture and product life cycle. The dimensions offer an overall perspective on all the parts composing these systems, and helps to analyse them one part at a time, thus simplifying the analysis of the complexities embedded in this structural change.

A crucial component to realize a smart, connected industry is the CPS. A CPS is based on computational devices collaborating and linking together the physical and the cyber worlds. Since it is a relatively new concept, a single, conclusive definition has not been agreed upon yet in the literature. Some definitions stress the architectural component, focusing on the interconnections of "smart" components (Lee, 2008), while others focus on the functions that this kind of system can provide, like self-reconfigurability and resilience. This means that both architectural and functional definitions exist. Furthermore, the distinction between IoT and CPS is not well established, as stated by Ning et al. (2015). Bughin et al. (2015) suggest that the main difference is based on the scope of integration: while loT connects several physical resources, and allows the exchange and usage of data, a CPS creates a software model of each physical resource, called a cyber twin, that does not operate under the place and time constraints of physical reality.

The most used, comprehensive and deep explanation of the different architectural parts that constitute a CPS is provided by Lee, Bagheri and Kao (2014), and is referred to as "the CPS Pyramid" - also known as $5 \mathrm{C}$ architecture. The CPS Pyramid provides a step-by-step bottom-up process for the construction of a CPS, from the implementation of data gathering devices to data management, elaboration and communication. The five steps, or layers, from the bottom of the CPS Pyramid, are:

1. Smart connection layer, which acquires data from the physical world, e.g. via a network of sensors, or through data collected within an enterprise manufacturing planning system;

2. Data-to-Information conversion layer, which provides data analytics applications, based on the realtime physical reality measurements enabled by the Smart Connection layer;

3. Cyber layer, which aims to populate cyber space with models of all the resources and their interactions, creating the quantum leap from a "simple" to a complex loT system (see Bagheri and Lee (2015));

4. Cognition layer, which synthesizes knowledge from lower levels of information and then define a decision process, establishing collaboration between the computer and the human user. This can be achieved with the use of different machine learning algorithms, such as artificial neural networks (Wilson and Russell, 2003), genetic algorithms (Aouadni and Rebai, 2016) and fuzzy-logic-based networks (Kim et al., 2008);

5. Configuration layer, which applies feedback mechanisms to provide supervisory or resilience services to the overall system. This means that the CPS can make decisions on the future states of its physical part, and actuate them.

This scheme is accepted by many authors (e.g. Monostori, 2014; Alam, Saini and El Saddik, 2015; Moraes, Lepikson and Colombo, 2015; Skowroński and Werewka, 2015; Jiang, Ding and Leng, 2016; Kang et al., 2016). 
Leveraging on the layers of the CPS Pyramid (Lee, Bagheri and Kao, 2014) we define a CPPS as a production system in which the technologies mentioned in the CPS Pyramid are embedded, allowing their transposition to a different and broader systemic perspectives (in contrast to the single-resourceperspective of the original CPS Pyramid). If more resources are connected, the production subsystem that is created can be considered as a whole, with clear boundaries defined by the connections; this is an loT setting. Accordingly, a CPS originates from the real-time connection of a single resource and its virtual twin, while a CPPS originates from the real-time connection of a set of resources with an loT setting and the virtual model of the entire set of resources, enabling the virtual model to take into account also the real-time interrelations between its parts. Therefore, every subsystem can be modelled with its specific "Cyber-Twin", and the top two levels of the pyramid can be applied to a cyber twin of the production subsystem (Ullrich, Voyiatzis and Weippl, 2016). Potentially, CPPS are not (technically) closed units, but can expanded as well as the connection between resources, and the complexity of the (modular) virtual model fed with real time data increases. Therefore, they can be described as open socio-technical systems, with a high degree of cross-linking of the physical, social and virtual world as well as an intelligent use of information and communication systems (Frazzon et al., 2013).

A collaborative and automatic communication between the different technological and human subsystems of a piece of equipment, a production line, or even the whole production system can substitute the traditional way of managing, planning and controlling activities. As a result, a CPPS generates new activities affecting social sustainability performance both from a management and technological standpoint.

\section{Towards an operational framework for Human-Centric Cyber Physical Production Systems}

Based on the literature review, an operational framework - the CPPS Functionality-Level Performance (CYFL) Matrix - was created in order for managers and engineers to identify and strategize around relevant performance areas in Human Centric CPPS. In the followings paragraphs, we first describe the framework's main axes, namely i) the CPPS Functionalities, which focus on the human and operational performance impacts, and ii) the CPPS levels of analysis, which focus on the technological hierarchy levels at which the CPPS enables intelligent human/machine interactions in the cyber- and physical spaces. Then, these two axes are combined to form the CyFLMatrix.

\subsection{CPPS Functionalities}

The first axis of the CyFL Matrix relates to the six Functionalities, which were synthesized from the literature and adjusted after the input from the expert interviews. The Functionalities are defined in terms of their objectives and intended outcomes, regarding social sustainability and operational performances, and are mutually distinct from each other with regard to the type of performance they affect.

They are divided into two macro-types; the first one focuses on optimizing the operations of existing systems by raising their actual performances to their maximum performance level. This type is labelled a "retaining" functionality. The second one focuses on the improvement and innovation of existing systems, raising their actual maximum performance level by changing and redefining tasks and jobs. This macro-type has been labelled an "enhancing" functionality. Practical examples of activities corresponding to each functionality have been found in the literature. 


\section{Functionality 1: Silent teacher}

The Silent Teacher functionality has the objective of improving the operator learning process, focusing on long-term improvements rather than short-term optimizations of the system. The Silent Teacher aims at reinforcing the efficacy of learning activities done by the operator of a CPPS within and outside the shop floor. Therefore, the silent teacher is an "enhancing" Functionality. The intended outcome of the Silent Teacher is to continuously improve the skills of the operators and ultimately make the company more competitive.

To exemplify, Ramos, Frasson and Ramachandran (2009) recount how relevant information is shown to the maintenance operator on a display or a wearable device. Gamification, virtual reality and augmented reality might be used by the Silent Teacher during training sessions within production or assembly lines, as shown by Wetzel et al. (2016). Moreover, augmented reality can help operators put into practice what they learn when they perform new tasks, to consolidate the conceptual part of the new knowledge.

\section{Functionality 2: Knowledge Manager}

The Knowledge Manager has the objective of analysing data gathered in production and extracting relevant information for defined stakeholders. The knowledge manager includes several solutions, such as the identification of best practices, critical resource identification, data entry and maintenance of knowledge databases, calculation and presentation of relevant key performance indicators and communication with other Functionalities and other related parts of the system. The intended outcome of it is to make the company learn and grow by better use of data for it to target the desired operational and social results. Therefore, the knowledge manager is an "enhancing" Functionality.

The knowledge manager can leverage cyber twins, i.e. simulation virtual machines, in order to investigate configurations of the production system that reach desired results, as in the case presented by Zhang et al. (2014). Lastly, the knowledge manager is able to update and store data in an effective and efficient way. To do so, a common group of ontologies is needed within a CPPS in order to have this kind of databases as a complete and shared resource (Lanz, Majuri and Tuokko, 2013).

\section{Functionality 3: Resource Integrator}

The Resource Integrator has the objective of enabling the system to be more flexible, striving to selfreconfigure itself with no setup costs. The intended outcome is to have a system that can quickly react to changes of the input factors, whether they are organizational, technological or environmental, so that it achieves agility, resilience and ultimately market flexibility. The resource integrator is an "enhancing" Functionality. The feature that particularly distinguishes the Resource Integrator is a feature known as plug \& produce. In fact, resources can be moved from a certain production cell, e.g. an assembly line of a product family, to another type of system dedicated either to the same or to a different product family, e.g. an assembly cell. Plug \& produce moves resources both physically and cybernetically without interferences to resources in the system that should not be affected by such a change (Ribeiro et al., 2015) and without reducing performances and unnecessary losses of time (Chirn and McFarlane, 2000).

Moreover, if a change in the production plant/subsystem/resource is made, the resource integrator reconfigures virtual models and flows accordingly, interacting with ERP, MES or similar systems.

\section{Functionality 4: Caregiver}

The Caregiver has the objective of minimising the negative impact of the tasks that operators perform on their health from a physical and mental standpoint, and consequently to improve their resulting 
performance. The intended outcome is healthier operators working at attractive, and in turn, improved production performances. The caregiver is a "retaining" Functionality.

From an ergonomics standpoint, the CPPS identifies the risks by using data collected from each operator and in general from the CPPS environment. These data have to be matched with the physical characteristics of the operator (height, strength, stamina, etc.) as shown by Pirvu, Zamfirescu and Gorecky (2014). When the risks are identified, the caregiver implements some changes to reduce and/or mitigate this risk, e.g., by communicating the risk to the operator through a wearable ICT device, or to the production manager for evaluation. The caregiver helps reduce operator's mental strain as well. For the case of maintenance work, the operator can access information about machine usage and previous maintenance activities, as illustrated by (e.g., Sheridan and Parasuraman, 2005; Hancock et al., 2015). Augmented reality can be employed to offer the operator information such as codes and names of components and to help him/her remember reparation procedures for machines that are less subject to breakdowns, as shown by Greer and Mark (2015).

\section{Functionality 5: Risk Manager}

The objective of the Risk Manager is the reduction of all the safety risks in the system. The intended outcome is to minimize the time loss due to equipment disruptions and injuries, and therefore create a healthier and safer workplace. The risk manager is a "retaining" Functionality.

The risk manager elaborates the information coming from the system resources states, which can be compared with expected states and propose action of change (Ding et al., 2014).

For example, in a context which requires the use of hearing protectors due to high noise levels, if the risk manager perceives the operator approaching an area with high noise, it alerts about the danger on screens near the risk area or directly on wearable devices, as reported by Srivastava, Abdelzaher and Szymanski (2012). The risk manager continuously receives information about the resources from their cyber twins. As a result, the risk manager puts predictive maintenance systems in place, by using the information about machine usages. A similar application is shown by Coraddu et al. (2014) and Susto et al. (2015). The risk manager would also be in charge of assessing the extent to which the system is exposed to risks of cyber-attacks and performs malfunction recognition, as additional failure modes.

\section{Functionality 6: Flow Master}

The Flow Master has the objective of managing and improving all the material and parts flows needed in the production system according to production requirements. This Functionality is more focused on operative performances than social sustainability ones. The flow master schedules the production activities in the best way possible, as the intended outcome is reduced lead times and improved quality.

The flow master scheduling activities must be robust to deal with changes regarding planning and execution. An example of this approach is proposed by Terzi and Cavalieri (2004), who give an evaluation framework for pre-emptively robust scheduling solutions. Parameters for production activities are selected by the flow master to get the best quality/time performance reachable by the process and/or its output. To realize such optimizations, the flow master needs to know the position of products or assembled parts, and their specific information (such as product family, variants, jobs already performed on the product, and similar). Moreover, it requires a knowledge base, a decision making unit, and the ability to identify its actual state, according to (Ribeiro et al., 2015). It is argued that a more reactive and flexible scheduling solution allows a more flexible structure for shift planning 
as well. In this way, the operators are given more freedom in managing their work time, hence enhancing their work-life balance.

\section{Summary}

Having defined the objectives and outcomes of CPPS functionalities, we now relate them to the technological enablers investigated in the literature. Table 5 summarizes some technologies and techniques, which have applications within each functionality. Some of these may have applications in more than one functionality. It must be noted that the implementation of CPS can be included in all functionalities, therefore this is not reported.

Table 5: Some technologies and techniques that can enable the CPPS Functionalities

\begin{tabular}{|c|c|}
\hline CPPS Functionality & Related technologies and techniques \\
\hline Silent Teacher & $\begin{array}{l}\text { Augmented reality; virtual reality; human-machine interface; virtual } \\
\text { interactive modelling of physical assets and procedures; advanced learning } \\
\text { models }\end{array}$ \\
\hline Knowledge Manager & $\begin{array}{l}\text { Big data analytics; forecasting technologies; clustering technologies; } \\
\text { artificial intelligence; Internet of things applied to sensors; advanced data } \\
\text { gathering technologies; simulation models; advanced database } \\
\text { management }\end{array}$ \\
\hline Resource Integrator & $\begin{array}{l}\text { Machine to machine communication protocols; automation standards } \\
\text { interpreters; adaptive and self-adaptive manufacturing equipment; } \\
\text { manufacturing system simulation models; big data analytics; human- } \\
\text { machine interfaces }\end{array}$ \\
\hline Caregiver & $\begin{array}{l}\text { Biometric data gathering sensors; strain assessment models and techniques; } \\
\text { collaborative robots; adaptive and self-adaptive manufacturing equipment; } \\
\text { augmented reality; exoskeletons; wearable devices }\end{array}$ \\
\hline Risk Manager & $\begin{array}{l}\text { Advanced statistical process control technologies; forecasting technologies; } \\
\text { Internet of things applied to sensors; wearable devices; automatic failure } \\
\text { mode identification and assessment techniques; risk evaluation models; } \\
\text { diffused safety-related actuators; predictive maintenance modules }\end{array}$ \\
\hline Flow Master & $\begin{array}{l}\text { Internet of Things applied to products and materials; advanced scheduling } \\
\text { solutions (multi agent systems, holonic systems, swarm intelligence, etc.); } \\
\text { material and product identification technologies; self-reconfigurable } \\
\text { equipment; diffused control systems, with warehouse-production data } \\
\text { integration; reconfigurable manufacturing systems }\end{array}$ \\
\hline
\end{tabular}

\subsection{CPPS levels of analysis}

The second axis of the CyFL Matrix relates to the underlying hierarchical structure for the analysis of CPPS. As outlined in the standards for performance measurement in manufacturing systems (ISO 22400, 2014), to define appropriately KPIs to be used to control the system, the identification of their scope is essential. Here, we leverage the equipment hierarchy model used in the international standard IEC 62264.1 (ANSI-ISA, 2000), as suggested by the RAMI 4.0 reference model, and adapt it to the problem of the analysis of a CPPS. The focus is therefore within the boundaries of a production system, and not considering the enterprise level. 
To do so, the concept of equipment will be extended to cover Cyber Physical Systems. We introduce two main changes from the original equipment hierarchy: first, a CPS can be built around human resources as well as around equipment. Second, resources that include Cyber-Physical features may not work at all the layers of the CPS Pyramid. For the scope of analysis, they will be considered as resources which are not fully integrated, but can be equated to CPSs. If a resource lacks features characteristic of a CPS, this would fall back to the equipment hierarchy case.

We identified three different hierarchical levels for resource aggregation in a CPPS (Figure 2). It is highlighted that physical resources are necessary to define the boundaries of level 1, 2 and 3 objects. Resources can be integrated with digital and virtual technologies to create a CPS according to the definition of Lee, Bagheri and Kao (2014), but this is not necessary for the analysis of the logical parts of a CPPS.

--- Please insert Figure 2: Hierarchy of the levels of analysis ---

An object of level 1 will be termed Smart Resource (SR). It is a cyber-physical subsystem tailored on one single resource. A smart resource is a set of: an assigned physical resource; automation chains (IT integration between sensors, database, computational centers and the physical resource, etc.) that are assignable to the physical resource and allow data gathering; and computational devices and models that use the gathered data. If a virtual model of the resource as a whole is present, this is referred to as the "cyber twin", and is used for scenario analysis and decision making. "Cyber twins" can be realized as dynamic databases and simulation software engines. Each object in a CPPS ideally has an assigned "cyber twin", and vice versa. The assigned physical resource can be categorized as a unit / work cell, in the terminology of the equipment hierarchy of IEC 62264.1.

An object of level 2 will be termed Smart Resource System (SRS). It refers to a system composed by a set of smart resources. A SRS is composed by the set of all SR that are part of a production subsystem, whose assigned physical resources are categorized as a process cell / production unit / production line, in the terminology of the equipment hierarchy. The subsystem can be identified according to the operative processes that the set of assigned physical resources carry out. All the SRs that compose a SRS, share the same production (operative) output(s). As for Smart Resources, it is possible that a SRS does not have all the features characteristic of a CPS; in fact, the existence of a "cyber twin" of the SRS, i.e. a virtual model reflecting the physical subsystem, may not necessarily be found. This kind of subsystem (SRS) can be defined by the physical layout boundaries of the physical part of the SRs that compose the SRS. In that sense, the boundaries of a SRS are crossed by material, information and product flows. Boundaries can also be set according to other concepts, e.g. value streams (a term from Lean Management literature). In setting the boundaries of a SRS, the interactions between the various SRs must also be considered. The information flows and the decision-making policies must also be included in the analysis.

An object of level 3 will be termed Smart Resource System Orchestra (SRSO). It is composed by the set of all SRSs that are part of a production system under analysis, which are connected directly (peer to peer) or indirectly (through the SRSO). A SRSO is composed by the set of all SRSs that are part of a production system; the union of all assigned physical resources is categorized as an Area, in the terminology of the equipment hierarchy. If the production system is composed of several areas, SRSOs 
can be scaled up to cover the whole site. In fact, from a performance measurement point of view, in a CPPS, resources will be connected throughout the areas and the site, flattening the need of distinction between those two scopes.

Furthermore, each object that can be classified into a level, is composed of a defined set of objects classified into the lower level; the actual composition of objects may change over time. It fact, each object can exist in a certain time and space frame. It must be noted that SRs can be re-organized dynamically in different SRSs, if changes occur in the flows or objectives of the production; that equipment can be shared or changed among SRs; etc.

It is quite clear that this peculiarity can bring some uncertainties about performance measures since the object for which performances are measured, may change over time. This is similar to the problem of batch production, where production performance metrics of a subsystem are derived from a multibatch standard, i.e. a mix of different products. The solution, in that case, is to robustly define aggregate measures (average values, variability analysis and so on) that can extract the wanted information about the system and provide metrics at a less granular level. If the manufacturing data management system of a production system is advanced enough, this distinction can allow an analysis of KPIs focusing on the single time-state of each object. For example, it should be possible to relate KPIs to a particular composition of human and equipment SRs within a SRS, whose composition changes over time (e.g. according to working shifts).

\subsection{CPPS Functionality-Level Performance Matrix}

Finally, the synthesis of this work as a whole has resulted in a tool able to connect relevant performance areas to the analysis framework proposed. This tool is in the form of a matrix, in which the CPPS functionalities and the CPPS levels of analysis are used as discrimination axes. The matrix is referred to as the CPPS Functionality-Level Performance (CyFL) Matrix (Figure 3). Each intersection demonstrates which performance areas are positively impacted by a Functionality, as enabled at each system level of analysis. The matrix will therefore be a useful tool to identify and organise performance areas to monitor in Human-Centric CPPS.

---- Please insert Figure 3: The CyFL Matrix, with the relevant performance areas distributed per Functionality and level of analysis ---

Performance areas included in the Matrix can be either well established, or emerging from the paradigms of future production systems (e.g. adaptability to a diverse workforce). In practice, performance areas will be monitored and controlled by means of suitable performance management systems, and implemented through the identification of related, case-oriented Key Performance Indicators (KPIs) and their target levels. It is suggested that within the same Functionality, performances related to lower levels of analysis are positively correlated to performances at higher levels of analysis.

In the next paragraph, we outline an operating method that is aimed at providing manufacturing companies with a reference guideline for using the CyFL Matrix.

\section{Guidelines for the use of the CyFL Matrix}

We suggest that the most suitable object of analysis for the CyFL Matrix is the single improvement project, carried out within the operations of a production system that is evolving towards a human- 
centric CPPS. To this end, we propose the following reference guidelines to identify the operative and social sustainability performance areas affected by the specific CPPS improvement project the manufacturing company has undertaken or plans to undertake.

\section{- Phase 0 - Acquisition of background information on the CPPS improvement project}

Here, the Analyst gathers information on the scope of the CPPS improvement project and on the assets and the processes it will affect. Relevant information for the CPPS improvement project under analysis can be retrieved from the Project Manager and already available project documentation.

\section{- Phase 1- Identification of the Level of Analysis}

The Analyst, using the definition of SR/SRS/SRSO as reference, identifies the levels of analysis affected by the CPPS improvement project under analysis, in order to identify and classify all the relevant performance areas inside the CyFL Matrix during the following phases.

\section{- Phase 2 - Identification of the Functionalities}

Now, the Analyst establishes which specific functionalities are impacted by the CPPS improvement project. This is achieved by decomposition of the improvement project into different sub-objectives, which are then mapped onto the related functionalities. To this end, the vertical axis of the CyFL Matrix and the description of the 6 functionalities are used as a reference.

\section{- Phase 3 - Compilation of the CyFL Matrix with performance areas}

During phase 3, the relevant performance areas to monitor are defined. Using the outputs of phases 1 and 2, the analysis has so far provided an overall view on the Levels of Analysis and on the Functionalities addressed by the CPPS improvement project. This preliminary information allows the Analyst to direct the focus of the compiling of the CyFL Matrix in the right direction.

As a preparatory step for the phase, the Analyst can initially fill the CyFL Matrix with all the Performance Areas that are already routinely measured by the manufacturing company. Usually, some proposals about performances to be measured are specified in the project documentation, (if not true for the case under analysis, it is possible to skip this preliminary compiling).

After this preparation, the definition and choice of relevant performance areas is carried out by systematically addressing each empty cell of the matrix to decide if any more important Performance Areas should be classified at each system level. To this end, the Analyst can organize a workshop assembling relevant stakeholders for the CPPS improvement project.

The output of this phase is the compiled CyFL Matrix reporting the Performance Areas that increase understanding and control of the project's operative and social outcomes, from a managerial point of view.

\section{Industrial use case}

The theory-building from the literature review and the expert interviews resulted in the CyFL Matrix for Manufacturing Analysts, but its use and usefulness needed to be examined. The following industrial case was therefore carried out to demonstrate and test the applicability of the proposed framework in addressing real-world CPPS improvement projects. 


\subsection{Whirlpool Zero Hours Quality department (ZHQ)}

The CyFL Matrix was applied to a case at Italian white goods manufacturer Whirlpool EMEA, specifically at the production site of Biandronno, and the focal CPPS improvement project was the improvement of the Zero Hours Quality department (ZHQ). At this site, Whirlpool EMEA produces medium- to high-end white goods, e.g. electric and microwave ovens, induction cookers and refrigerators. The production site also hosts the Product Engineering \& Development department and the Operations Excellence Department, who coordinate all the activities of industrial engineering for all the European factories, providing multidisciplinary competences working to improve the manufacturing footprint.

In Whirlpool ZHQ, the statistical quality control simulates the first usage of Whirlpool products at the customer's premises. The statistical quality control does not replace quality tests that are performed during the whole production process, but it is done in addition to them.

At present, the ZHQ system is comprised of a specific application hosted in a dedicated personal computer, where the testing rules can be programmed, and fixed testing stations, where programmable sequence of tests can be started and managed by an operator according to the product under test. Each personal computer is also equipped with a laser scanner used to read product barcodes and identify both the product model code and the serial number.

To improve the current ZHQ, a project leveraging on CPPS was initiated in 2016. At the beginning of the project, the CyFL Matrix was used to spot the operational and social performance areas impacted by the new CPPS. Three of the researchers involved the project manager and one senior engineer from the Appliance Testing Unit to use the CyFL matrix. The results of the application of the CyFL Matrix to Whirlpool's ZHQ improvement project are described step by step in the following paragraph, according to the approach proposed in Section 4.3.

\subsection{Application of the CyFL Matrix to Whirlpool ZHQ}

\section{Phase 0 - Acquisition of background information on the CPPS improvement project}

Preliminary information on the ZHQ improvement project were collected from Whirlpool project manager and extracted from the project documents already available. Four main complementary CPPS strategies were identified:

- CPPS strategy 1 "Usage of Portable Testing Stations". Portable and programmable testing stations, equipped with embedded computing power, multipurpose sensors (thermocouple, etc.), actuators and wireless communication, will be introduced in ZHQ.

- CPPS strategy 2 "Enhanced Operator Interaction". Since the operators play a very important role in ZHQ, mobile devices - smartphones and tablets - will be introduced in order to support their activities in real-time. They will be able to create new testing rules and be guided by the system on the fly and in a more convenient way. To this end, two new interface applications will be created.

- CPS strategy 3 "Auto-Reconfiguration of the Portable Testing Stations". Data flows, generated by tests and communicated Machine-to-Machine between the portable testing stations, will be used to modify automatically the program behaviour in a permanent or temporary way, e.g. activating test extensions based on current test results and historical data.

- CPS strategy 4 "Enhanced Information Interpretation". In the current situation, quality testing is based on threshold rules, focused on the identification of the most critical situations. In this strategy, the adoption of a cloud based analytical tool able to process real time data will make it 
possible to highlight a wider set of potential problems by comparing the dynamic behaviour of the components under test to the expected one.

\section{Phase 1- Identification of the Level of Analysis}

In phase 1, taking the definition of the 3 levels of analysis proposed in the CyFL Matrix as reference, the most appropriate level was associated to each CPPS strategy (1-4). Accordingly:

- CPPS strategy 1 affects the SR Level, i.e. the single testing station and its related sensors and software modules.

- CPPS strategy 2 affects the SRS level, i.e. the quality-testing stage of the production process. The set of resources belonging to this SRS are the testing stations and the human operators, connected to the ZHQ system by the means of tablets/smartphones. It should be noted that the human resources, here, are not connected in the means; in fact, no data regarding the human operator is gathered or processed/stored by the system.

- CPPS strategy 3 affects the SRS level, in that it impacts the ability and rules of reconfiguration and control of the affected SRs.

- CPPS strategy 4 affects the SRS level, specifically the Cyber Twins network and their cognition abilities, as well as the reconfiguration rules.

Compared to the "nominal" CyFL matrix, we can see that in this CPPS improvement project, the prognosticated impacts do not reach up all the way to the SRSO level, where all the system's SRS and SR are impacted as an entire system. Nevertheless, the participants in the project expressed an interest in predicting some impacts beyond the SRS level, but not in a full-system-encompassing way; therefore, in this particular use case the researchers accommodated the interests of the participants to consider a higher analysis level, but only within the scope of their mandate, and called this intermediate level "Plant level".

\section{Phase 2-Identification of the Functionalities}

The objectives of Whirlpool's ZHQ improvement project were provided by the Project Manager. These functions were then mapped onto the 6 Functionalities of the CyFL Matrix, as seen in Table 6.

Table 3. CPPS Improvement objectives and their corresponding Functionalities

\begin{tabular}{|l|l|}
\hline \multicolumn{1}{|c|}{ CPPS improvement project at Whirlpool ZHQ } & \multicolumn{1}{|c|}{$\begin{array}{c}\text { Corresponding functionalities of the } \\
\text { CyFL Matrix }\end{array}$} \\
\hline $\begin{array}{l}\text { Providing the operator with real time instructions during the } \\
\text { sequence of tasks }\end{array}$ & Caregiver \\
\hline $\begin{array}{l}\text { Teaching the operator better procedures to check and } \\
\text { measure the products }\end{array}$ & Silent Teacher \\
\hline Reprogramming and reconfiguring the testing stations & Resource Integrator \\
\hline Automatic input/output to change the product's state & Flow Master \\
\hline $\begin{array}{l}\text { Gathering, storage and processing industrial data for real- } \\
\text { time and/or historical analysis. }\end{array}$ & Knowledge Manager \\
\hline
\end{tabular}

It can be noticed that five out of the six CyFL Matrix's functionalities are covered by the ZHQ project, while the Risk Manager was not included in the analysis as no interventions with respect to this functionality were defined. 


\section{Phase 3-Compilation of the CyFL Matrix with performance area}

After identifying the levels of analysis and the functionalities, the project manager and senior engineer from Appliance Testing were involved in a workshop to identify which performance areas to monitor. Before the workshop, an initial compiling of the CyFL Matrix was made, considering the performance areas that were already suggested inside the project documents provided by the company (those are highlighted in blue in Figure 4). The initial compiling of the CyFL Matrix was then used at the beginning of the workshop in order to stimulate discussion among the participating stakeholders. As explained before, they were also interested in mapping the contribution of the ZHQ improvement to the overall Plant level, in order to support them in their communication towards the corporate level and the project sponsor. The impacted Performance Areas (those are reported in black in Figure 4) and the complete CyFL Matrix analysis for Whirlpool ZHQ are reported in Figure 4 and in Table 7.

--- Please insert Figure 4 CyFL Matrix of Whirlpool's ZHQ with identified performance areas for the project (pre-established performance areas found in project documentation are in blue) ---

Table 4: CPPS Improvement impacts within each of the identified Functionalities

\begin{tabular}{|c|c|}
\hline $\begin{array}{c}\text { Relevant } \\
\text { Functionalities }\end{array}$ & Performance impacts in Whirlpool ZHQ CPPS Improvement project \\
\hline Silent Teacher & $\begin{array}{l}\text { - Operator learning: the operator's learning curve will improve because the } \\
\text { information is delivered to the operator when he/she needs it. } \\
\text { - Human error incidence: the improvement of the learning process will affect } \\
\text { the rate of human errors caused by a lack of knowledge. This is the cumulated } \\
\text { effect, on a SRS level, of the improved operators' learning. } \\
\text { - Human Capital: learning improvements will result in an increasing of the } \\
\text { knowledge, skills and competences collectively hold by operators, resulting in } \\
\text { a higher human capital. } \\
\text { - Employee satisfaction: more competences and better performance will } \\
\text { enhance the Employee Satisfaction level. }\end{array}$ \\
\hline $\begin{array}{l}\text { Knowledge } \\
\text { Manager }\end{array}$ & $\begin{array}{l}\text { - Information capital: more information about product's malfunctions and } \\
\text { defects will be gathered by each SR (i.e., the portable testing station) and } \\
\text { made available for analysis. } \\
\text { - Communication Quality: the quality of Machine-to-Human communication } \\
\text { and the Human-to-Machine communication will be improved thanks to } \\
\text { enhanced interfaces on mobile devices. Additionally, Machine-to-Machine } \\
\text { communication between portable testing stations will be introduced. } \\
\text { - Knowledge and Innovation: the ability to spot, analyse and communicate new } \\
\text { information will allow the plant to have new knowledge on the product and } \\
\text { introduce new preventive actions. } \\
\text { External Quality: thanks to the identification and retention of non- } \\
\text { conforming items, more proper-functioning products will be delivered to the } \\
\text { market, with a positive impact on the External Quality of the plant. } \\
\text { Plant Accessibility and Work-life balance: plant accessibility refers to the } \\
\text { future possibility of accessing the digitalized ZHQ anytime, anywhere. In fact, } \\
\text { if testing data and/or rule modification will be done by means of a digital }\end{array}$ \\
\hline
\end{tabular}




\begin{tabular}{|c|c|}
\hline & $\begin{array}{l}\text { application, the need for the operator to be on field is less crucial. This } \\
\text { dimension is intended to positively impact on the flexibility of the work and, } \\
\text { thus, on the work-life balance of operators. }\end{array}$ \\
\hline $\begin{array}{l}\text { Resource } \\
\text { Integrator }\end{array}$ & $\begin{array}{l}\text { - Process Flexibility: each SR (portable testing stations) will have a more } \\
\text { flexible testing process thanks to the enhanced programmability and auto- } \\
\text { reconfiguration. } \\
\text { - Volume Flexibility: the SRS (ZHQ) will be able to react to variation in the } \\
\text { demand, thanks to the possibility of removing and adding portable testing in } \\
\text { an easy way. } \\
\text { - Expansion Flexibility: portable testing stations will enter/exit the system in a } \\
\text { plug and play mode, understanding context, local network, etc. Accordingly, } \\
\text { changes in the manufacturing capacity will require less time and cost. } \\
\text { Market flexibility: the flexibilities introduced at the SR and SRS level will } \\
\text { contribute to improving the capability of the plant to deal with customised } \\
\text { products and frequent product changes, providing a better response to } \\
\text { customers' requests. }\end{array}$ \\
\hline Caregiver & $\begin{array}{l}\text { - Well-being: the possibility to have real-time guided operations by means of } \\
\text { digital devices represents a form of cognitive automation that can reduce the } \\
\text { psychological strain of the operator and, thus, enhance his/her well-being. } \\
\text { - Time loss due to lack of instructions: this is the SRS level performance directly } \\
\text { building on the guided operations. The support provided to operators will } \\
\text { decrease the time spent on non value-added activities, such as searching for } \\
\text { information and help. } \\
\text { - Productivity: by reducing the time loss due to lack of instruction, it will be } \\
\text { possible to perform more tests during each shift, meaning a higher } \\
\text { productivity for the ZHQ. } \\
\text { Internal quality: having more healthy and productive operators will positively } \\
\text { affect the quality control process and, thus, the internal quality level. }\end{array}$ \\
\hline Flow Master & $\begin{array}{l}\text { - Time Efficiency: the automatic input/output will enable the system to do } \\
\text { automatically all the tests in a certain sequence, when the product is plugged } \\
\text { in and recognised. This will lower the number of non-value-added activities to } \\
\text { be carried out by the operator for setup activities. } \\
\text { Routing Flexibility: It refers to the ability of the ZHQ system to continue } \\
\text { testing given products mix in the presence of internal disturbances, such as } \\
\text { tool breakages, controller failures or machine breakdowns. High levels of this } \\
\text { kind of flexibility are reached since the products can be tested via several } \\
\text { stations, meaning each test sequence can be performed on more than one SR } \\
\text { (i.e., the portable testing station) inside the system. } \\
\text { Cost efficiency: it will be possible to reach higher utilization of the SRs and } \\
\text { lower testing processes' costs, meaning that the cost efficiency of the plant } \\
\text { will increase. }\end{array}$ \\
\hline
\end{tabular}

It can be noticed that 16 new Performance Areas were identified, especially in relation to social sustainability, providing the stakeholders with a wider understanding of the performances to 
measure, in order to guide the implementation of the CPPS strategies and monitor their full impacts. To this end, starting from the identified Performance Areas, suitable indicators and their related metrics are to be selected during the following step of the project.

\section{Discussion and Conclusions}

The evolution of manufacturing production systems towards human-centric CPPS will not be done in one single step but the evolution will be achieved thanks to multiple steps (Qin et al., 2016; Freddi, 2017). From a manufacturer's perspective, each step can be seen as an improvement project, intended as a modification of the current production system that is made with the objective of enhancing the operational and social sustainability performance of the production system itself (Garetti and Taisch, 2012; Gökan May et al., 2015; Romero et al., 2015).

According to this perspective, to progress towards human-centric CPPS and embrace the Industry 4.0 paradigm in a socially sustainable way, identifying and measuring social aspects in manufacturing, and determining their interaction with production and operative dimensions is of paramount importance (Winroth et al., 2016; Sutherland et al., 2016; Peruzzini and Pellicciari, 2017).

In this paper, we presented a review of the literature on social sustainability, CPPS and performance measurement in production systems. Then, we developed the CyFL Matrix, a literature-based framework to identify and organize operational and social sustainability performances stemming from six functionalities enabled by CPPS at three levels of analysis. The CyFL Matrix was also accompanied by a guideline aimed at helping companies in using the framework. Finally, the application of the CyFL Matrix and the related guideline was illustrated by using a case study concerning the CPPS improvement project carried out at the Zero Hours Quality department of Whirlpool EMEA in Biandronno.

Our work have several implications for theory and practice, which we outline in the followings.

\subsection{Contributions}

Our study offers three main contributions to current research on human-centric CPPS.

First, we provide a joint literature review on innovative technologies associated with the concept of CPPS and Industry 4.0 alongside social sustainability in manufacturing operations, which can be used as a base for future studies on Human-Centric Cyber-Physical Systems. To the best of our knowledge, there are no other reviews jointly analysing the state-of-the-art on the interrelation among technological and social domains in manufacturing operations.

Second, the CPPS Functionalities provided in this work respond to the need of describing the different Industry 4.0 applications that can create significant impacts on a production system. An impact is deemed significant if it has the potential to increase the systems' performances, or if it enables new functions.

Accordingly, we respond to numerous authors (e.g. Frazzon et al., 2013) highlighting that in the current literature there is a lack of clear understanding about how operative and social performances of a production system could be affected by the implementation of CPPS.

Moreover, this work provides a coherent description of CPPS functionalities from a more managerial and outcome-driven perspective on technology innovations. This is a new approach to the matter that complements the usual engineering-driven, technical perspective focusing on the detailed exploration of each function as enabled by technology innovations. It connects CPPS to the concept of operational and sustainability-oriented performance, thus fostering clarity and understanding within an area that 
increasingly runs the risk of becoming more complex and fragmented, and stimulating managers' willingness to increase the social performances of their production systems.

Third, in the literature there is a dearth of instruments to identify relevant Performance areas for a Human-Centric CPPS, as noted by Searcy, Dixon and Neumann (2016). We have not found any other methods and tools based on a thorough literature review, encompassing the structured categorization of performances in CPPS, and considering production and social sustainability aspects in a holistic way. The CyFL Matrix contributes to this particular gap by providing a cross-view of CPPS Functionalities (focusing on the objective of each implementation) crossed with the different hierarchical system levels of CPPS (focusing on the system scope). This view enables a structured representation of the impacts on performance that can be achieved with a stratified CPPS implementation, thus creating the base for linking social sustainability at operative level to strategic results, as described by Garetti and Taisch (2012), in CPPS.

Our work has also practical implications. Specifically, the CyFL Matrix and its related guideline work as a support tool for manufacturing managers and engineers willing to identify, organize and monitor the impacts of CPPS they are considering to introduce/design. The CyFL Matrix gives a comprehensive understanding of the benefits of implementing a CPPS-oriented solution and facilitates the identification and organization of performances on production and social sustainability aspects. Accordingly, the CyFL Matrix and its related guideline can be useful to highlight performance impacts the manufacturing practitioner may not have considered otherwise.

\subsection{Limitations and directions for future research}

Our contributions should be interpreted in light of the limitations of this study, which we suggest to be addressed in future research.

First, we carried out a narrative literature review because of the novelty and multi-disciplinary nature of our study. Although we combined multiple searches and applied a well-defined review process in order to guarantee the comprehensiveness of the results and to reduce the risk of bias, future studies based on a systematic literature reviews would be valuable.

Second, the CPPS Functionalities were classified on the basis of objectives that can be pursued with the implementation of technologies. Therefore, this study does not report a univocal link between specific technologies and outcomes. We suggest that future research should investigate this relationship in order to provide further guidance on the best technologies available to realize each Functionality.

Third, while the proposed CyFL Matrix provides a view of the performance areas impacted by the CPPS functionalities at different levels, key performance indicators in each area are not identified. We suggest that future work may leverage on our results and define the most suitable key performance indicators to measure, track and improve the performance in each area.

Fourth, our study focus was limited to social sustainability aspects related to human operators within the organization, since they are recognized as a crucial stakeholder for manufacturing organizations. In future, researchers could also address other social sustainability aspects related to external stakeholders, such as customers, suppliers and the community. Further, environmental sustainability was delimited from the scope of our investigation. Future studies integrating environmental performances would be useful in order to support a holistic view of the overall sustainability of CPPS. 
Finally, the focus of the research was limited to the operations level and the operations phase in the life cycle of a production plant. The integration of other hierarchical levels (e.g. enterprise), plant lifecycle phases (e.g. plant design, ramp-up, refurbishing and dismissing), and the interrelation between a CPPS and its performance impacts on the entire value chain, require further elaboration.

\subsection{Conclusions}

Identifying and measuring social aspects in manufacturing, and determining their interaction with production and operative dimensions is crucial to progress towards the Industry 4.0 paradigm in a socially sustainable way (Romero et al., 2015; Sutherland et al., 2016), and to shape the competitive and human-centric workplaces of the future (Peruzzini and Pellicciari, 2017: Gregori et al., 2017).

Without clear frameworks, methods and tools to integrate human and social sustainability aspects in the design and deployment of future CPPS, there is the risk these aspects will be overlooked or considered as an add-on to core value-creation processes (Jiang, Ding and Leng, 2016; Pirvu, Zamfirescu and Gorecky, 2014; Romero et al., 2016, Peruzzini and Pellicciari, 2017) .

The present work is intended to take a step forward synthesizing the diverse literature streams on social sustainability, CPPS and performance measurement in production systems. Based on the literature findings, it then conceptualizes six main functionalities enabled by a CPPS and three levels of analysis of a CPPS. These are thus combined into a novel framework - the CyFL Matrix - that can help both industrial and research stakeholders to navigate the operational and social sustainability performance impacts of improvement projects towards human-centric CPPS. Finally, the CyFL Matrix and its related guideline are applied to an industrial use case to provide concrete evidence of the results achievable by using the proposed framework in manufacturing practice.

In doing so, the present study contributes to set the stage for future research aimed at supporting manufacturing companies in the realization of human-centric CPPS, future highly digitalized production systems where operational and social sustainability aspects are managed proactively to achieve the best for people and competitiveness.

\section{Acknowledgements}

The Authors would like to thank Whirlpool EMEA for participating in the research. The Authors are especially thankful to Pierluigi Petrali and Claudio Turrin for the valuable material and information, and helpful comments and suggestions.

This work is partly funded through the European Union's Horizon 2020 research and innovation programme under grant agreement No 680633

\section{References}

ActionPlanT (2012) ' The ActionPlanT Roadmap for Manufacturing 2.0'. Available at: http://www.actionplant-project.eu/images/stories/roadmap.pdf

Adler, P. and Clark, K. (1991) 'Behind the learning curve: a sketch of the learning process'. 
Adler, P. S. and Clark, K. B. (1991) 'Behind the Learning Curve: A Sketch of the Learning Process'. Available at: http://papers.ssrn.com/abstract=979437 (Accessed: 27 May 2016).

Ajai, J., Jainb, P. K., Chanc, T. S. F. and Singh, S. (2013) 'A review on manufacturing flexibility', International Journal of Production Research, 51(19), pp. 5946-5970. doi: 10.1007/978-3-540-854142_3.

Alam, K. M., Saini, M., \& El Saddik, A. (2015). Toward social internet of vehicles: Concept, architecture, and applications. IEEE Access, 3, 343-357.

Amador, L. B., Nicolás, Á. L. and Vila, L. E. (2008) 'Education and competence mismatches: job satisfaction consequences for workers', XVI Jornadas ASEPUMA-IV Encuentro Internacional Recta, 16(1).

ANSI-ISA (2000) 'Enterprise-Control System Integration Part 1: Models and Terminology', 3(July), pp. 1142.

Anzanello, M. J. and Fogliatto, F. S. (2011) 'Learning curve models and applications: Literature review and research directions', International Journal of Industrial Ergonomics, 41(5), pp. 573-583. doi: 10.1016/j.ergon.2011.05.001.

Aouadni, I. and Rebai, A. (2016) 'Decision support system based on genetic algorithm and multi - criteria satisfaction analysis ( MUSA) method for measuring job satisfaction', Annals of Operations Research. Springer US. doi: 10.1007/s10479-016-2154-z.

Aouadni, I., Rebaï, A., Christodoulakis, N. and Siskos, Y. (2014) 'Job satisfaction measurement: The multicriteria satisfaction analysis', International Journal of Applied Decision Sciences, 7(2), pp. 190-207.

Arena, M., Azzone, G., Bengo, I (2015). "Performance measurement for Social Enterprises". VOLUNTAS, vol. 26 (2), p. 649-672, ISSN: 0957-8765

Arena, M., Duque Ciceri, N., Terzi, S., Bengo, I., Azzone, G. and Garetti, M. (2009) 'A state-of-the-art of industrial sustainability: definitions, tools and metrics', International Journal of Product Lifecycle Management, 4(1-3), pp. 207-251.

Askenazy, P. (2004) 'Shorter Work Time, Hours Flexibility, and Labor Intensification', Eastern Economic Journal, 30(4), 603-614.

Attri, R. and Grover, S. (2015) 'Production system life cycle: An inside story', International Journal of Industrial and Systems Engineering, 19(4), pp. 483-514.

Bagheri, B. and Lee, J. (2015) Big future for cyber-physical manufacturing systems. Available at: http://www.designworldonline.com/big-future-for-cyber-physical-manufacturing-systems/.

Baldock, R., James, P., Smallbone, D. and Vickers, I. (2006) 'Influences on small-firm compliance-related behaviour: The case of workplace health and safety', Environment and Planning C: Government and Policy, 24(6), pp. 827-846. doi: 10.1068/c0564.

Baur, C. and Wee, D. (2015) 'Manufacturing's next act', McKinsey \& Company. Available at: https://www.mckinsey.com/business-functions/operations/our-insights/manufacturings-next-act

Bayindir, Z. P., Birbil, Ş. I. and Frenk, J. B. G. (2007) 'A deterministic inventory/production model with general inventory cost rate function and piecewise linear concave production costs', European Journal of Operational Research, 179(1), pp. 114-123. doi: 10.1016/j.ejor.2006.03.026. 
Bengo, I., Arena, M., Azzone, G., Calderini, M. (2016). Indicators and metrics for social business: a review of current approaches. Journal of Social Entrepreneurship, 1 (2), 1-24.

Berlin, C and Adams C (2017). Production Ergonomics: Designing Work Systems to Support Optimal Human Performance, pp. 241-258. London: Ubiquity Press. DOI: https://doi.org/10.5334/bbe.m. License: CC-BY 4.0

Berlin, C., Barletta, I., Fantini, P., Georgoulias, K., Hansich, C., Lanz, M., Latokartano, J., Pinzone, M., Stahre, J., Taisch, M. and Tuokko, R. (2015) 'Prerequisites and Conditions for Socially Sustainable Manufacturing in Europe 's Future Factories - results overview from the SO SMART Project'.

Berlin, C., Dedering, C., Jónsdóttir, G. R. \& Stahre, J. (2013). Social sustainability challenges for European manufacturing industry: attract, recruit and sustain. In IFIP International Conference on Advances in Production Management Systems (pp. 78-85). Berlin, Heidelberg: Springer.

Bettoni A., Cinus M., Sorlini M., May G., Taisch M., Pedrazzoli P. (2014). Anthropocentric Workplaces of the Future Approached through a New Holistic Vision. In: Grabot B., Vallespir B., Gomes S., Bouras A., Kiritsis D. (eds) Advances in Production Management Systems. Innovative and Knowledge-Based Production Management in a Global-Local World. APMS 2014. IFIP Advances in Information and Communication Technology, vol 439. Springer, Berlin, Heidelberg

Boston Consulting Group (2015). Man and Machine in Industry 4.0 How Will Technology Transform the Industrial Workforce Through 2025.2 Available https://www.bcgperspectives.com/content/articles/technology-business-transformation-engineeredproducts-infrastructure-man-machine-industry-4/

Boyer, K. K., and Lewis, M. W. (2002). 'Competitive priorities: investigating the need for trade-offs in operations strategy'. Production and Operations Management, 11(1), 9-20.

Brown, K. A., Willis, P. G. and Prussia, G. E. (2000) 'Predicting safe employee behaviour in the steel industry: the development and test of a socio-technical model', Journal of Operations Management, 18(4), pp. 445-468.

Bughin, J., Chui, M. and Manyika, J. (2015) An executive's guide to the Internet of Things. Available at: mckinsey.com/Insights/Business_Technology/An_executives_guide_to_the_Internet_of_Things?cid=digi tal-eml-alt-mip-mck-oth-1508.

Chen, D., Heyer, S., Ibbotson, S., Salonitis, K., Steingrímsson, J. G. and Thiede, S. (2015) 'Direct digital manufacturing: Definition, evolution, and sustainability implications', Journal of Cleaner Production, 107, pp. 615-625. doi: 10.1016/j.jclepro.2015.05.009.

Chirn, J. L. and McFarlane, D. C. (2000) 'A holonic component-based approach to reconfigurable manufacturing control architecture', Proceedings - International Workshop on Database and Expert Systems Applications, DEXA, 2000-Janua, pp. 219-223. doi: 10.1109/DEXA.2000.875030.

Coraddu, A., Oneto, L., Ghio, A., Savio, S., Anguita, D. and Figari, M. (2014) 'Machine learning approaches for improving condition-based maintenance of naval propulsion plants', Proceedings of the Institution of Mechanical Engineers, Part M: Journal of Engineering for the Maritime Environment, 230(1), pp. 136-153. doi: 10.1177/1475090214540874. 
Cronin, P., Ryan, F., \& Coughlan, M. (2008). 'Undertaking a literature review: a step-by-step approach'. British Journal of Nursing, 17(1), 38-43.

Csikszentmihalyi, M. (1997). Finding flow: The psychology of engagement with everyday life. Basic Books.

Dai, W., Dubinin, V. N. and Vyatkin, V. (2014) 'Migration from PLC to IEC 61499 using semantic web technologies', Systems, Man, and Cybernetics: Systems, IEEE Transactions on, 44(3), pp. 277-291. doi: 10.1109/TSMCC.2013.2264671.

Darr, W. and Johns, G. (2008) 'Work strain, health, and absenteeism: A meta-analysis.', Journal of Occupational Health Psychology, Vol 13(4), pp. 293-318.

de Burgos Jimenez, J., and Céspedes Lorente, J. J. (2001). 'Environmental performance as an operations objective'. International Journal of Operations \& Production Management, 21(12), 1553-1572.

De Toni, A., and Tonchia, S. (2001). 'Performance measurement systems-models, characteristics and measures'. International Journal of Operations \& Production Management, 21(1/2), 46-71.

Dey, A. and Mann, D. D. (2010) 'Sensitivity and diagnosticity of NASA-TLX and simplified SWAT to assess the mental workload associated with operating an agricultural sprayer.', Ergonomics, 53(7), pp. 848857. doi: 10.1080/00140139.2010.489960.

Ding, X., Li, Y., Belatreche, A. and Maguire, L. P. (2014) 'An experimental evaluation of novelty detection methods', Neurocomputing, 135, pp. 313-327. doi: 10.1016/j.neucom.2013.12.002.

Doran, J. A. and Van der Graaf, G. (1996) 'Tripod-BETA: incident investigation and analysis', in International Conference on Health, Safety and Environment in Oil and Gas Exploration and Production.

Dworschak, B. and Zaier, H. (2014). Competences for cyber-physical systems in manufacturing - first findings and scenarios. 8th International Conference on Digital Enterprise Technology - DET 2014 "Disruptive Innovation in Manufacturing Engineering towards the 4th Industrial Revolution. Procedia CIRP 25, pp. $345-350$

Effra (2013) Factories of Future: 2020 Roadmap. Available at: http://www.effra.eu/factories-futureroadmap

Eijnatten, F. v. (2000) 'From intensive to sustainable work systems: The quest for a new paradigm of work', in TUTB/SALTSA Conference: Working Without Limits: Re-Organising Work and Reconsidering Workers' Health. Brussels.

Elo, S., and Kyngas, H. (2008). 'The qualitative content analysis process'. Journal of Advanced Nursing, 62(1), pp. 107-115.

Evans, M. O. T. W. M. (1997) 'Availability-based maintenance within an asset management programme', Journal of Quality in Maintenance Engineering, 3(4), pp. 221-232. doi: 10.1108/13552519710176854.

Falck, A. C. (2009) Ergonomics Methods and Work Procedures in Car Manufacturing for improvement of quality, productivity and health at work. Available at: http://publications.lib.chalmers.se/publication/93803?pubid=27090 
Fantini, P., Palasciano, C., Taisch, M., Berlin, C., Adams, C. and Stahre, J. (2014) 'Socially Sustainable Manufacturing: Exploring the European Landscape', IFIP Advances in Information and Communication Technology, 439(PART 2), pp. 474-481. doi: 10.1007/978-3-662-44736-9_58.

Fantini, P., Tavola, G., Taisch, M., Barbosa, J., Leitao, P., Liu, Y., Sayed, M. S., Lohse, N., Milano, P., Tavola, G. and Taisch, M. (2016) 'Exploring the integration of the human as a flexibility factor in CPS enabled manufacturing environments: methodology and results', pp. 0-5. doi: 10.1109/IECON.2016.7793579.

Fasth-Berglund, A. and Stahre, J. (2013) 'Cognitive automation strategy for reconfigurable and sustainable assembly systems', Assembly Automation, 33, pp. 294-303. doi: 10.1108/AA-12-2013-036.

Ferdows, K. and De Meyer, A. (1990) 'Lasting improvements in manufacturing performance: In search of a new theory', Journal of Operations Management, 9(2), pp. 168-184. doi: 10.1016/02726963(90)90094-T.

Fernandez, E. and Marley, R. M. (1998) Applied Occupational Ergonomics: A Textbook. Kendall-Hunt Publishing.

Fernandez, J. and Goodman, M. (2000) 'Ergonomics in the workplace', in Proceedings of the 8th Annual North American Waste-to-Energy Conference (NAWTEC 8).

Fiasché, M., Pinzone, M., Fantini, P., Alexandru, A., and Taisch, M. (2016). 'Human-centric factories 4.0: A mathematical model for job allocation'. In Research and Technologies for Society and Industry Leveraging a better tomorrow (RTSI), 2016 IEEE 2nd International Forum on (pp. 1-4). IEEE.

Frazzon, E. M., Hartmann, J., Makuschewitz, T. and Scholz-Reiter, B. (2013) 'Towards socio-cyberphysical systems in production networks', Procedia CIRP. Elsevier B.V., 7, pp. 49-54. doi: 10.1016/j.procir.2013.05.009.

Freddi, D. Digitalisation and employment in manufacturing. AI \& SOCIETY, pp. 1-11.

Fujita, M., Kato, R. and Tamio, A. (2010) 'Assessment of operators' mental strain induced by hand-over motion of industrial robot manipulator', in 19th International Symposium in Robot and Human Interactive Communication. IEEE, pp. 361-366.

Fynes, B. and Voss, C. (2001) 'A Path Analytic Model of Quality Practices, Quality Performance, and Business Performance', Production and Operations Management, 10(4), pp. 494-513. doi: 10.1111/j.1937-5956.2001.tb00089.x.

Garetti, M. and Taisch, M. (2012) 'Sustainable manufacturing: Trends and research challenges', Production Planning and Control, 23(2-3), pp. 83-104. doi: 10.1080/09537287.2011.591619.

Geiger, F. and Reinhart, G. (2016) 'Knowledge-based machine scheduling under consideration of uncertainties in master data', Production Engineering. Springer Berlin Heidelberg, 10(2), pp. 197-207. doi: 10.1007/s11740-015-0652-5.

Gerr, F., Fethke, N. B., Anton, D., Merlino, L., Rosecrance, J., Marcus, M. and Jones, M. P. (2014) 'A Prospective Study of Musculoskeletal Outcomes Among Manufacturing Workers: II. Effects of Psychosocial Stress and Work Organization Factors', Human Factors: The Journal of the Human Factors and Ergonomics Society, 56(1), pp. 112-130. doi: 10.1177/0018720813487201. 
Golden, L., Henly, J. R., \& Lambert, S. (2013). Work schedule flexibility: A contributor to happiness?. Journal of Social Research \& Policy, 4(2), 107.

Goldin, C. (2016) 'Human Capital', Handbook of Cliometrics. Heidelberg, Germany: Springer Verlag.

Greer, J. and Mark, M. (2015) 'Evaluation Methods for Intelligent Tutoring Systems Revisited', International Journal of Artificial Intelligence in Education, pp. 1-6. doi: 10.1007/s40593-015-0043-2.

Gregori, F., Papetti, A., Pandolfi, M., Peruzzini, M., \& Germani, M. (2017). Digital manufacturing systems: a framework to improve social sustainability of a production site. Procedia CIRP, 63, 436-442.

Hancock, B. P. A., Jagacinski, R. J., Parasuraman, R., Wickens, C. D., Wilson, G. F. and Kaber, D. B. (2015) 'Human-Automation Interaction Research: Past, Present, and Future', pp. 9-14. doi: 10.1177/1064804613477099.

Hancock, P. A. and Chignell, M. H. (1986) 'Toward a theory of mental workload: stress and adaptability in human-machine systems'. Proceedings of the International IEEE Conference on Systems, Man and Cybernetics, 378-383.

Hankel, M. (2015) 'The Reference Architectural Model Industrie 4.0 (RAMI 4.0)', ZWEI: Die Elektroindustrie, 1(April), pp. 1-2.

Harun, K., Cheng, K. and Wibbelmann, M. (2008) 'RFID-enabled aerospace manufacturing: Theoretical models, simulation and implementation issues', 2008 IEEE International Conference on Industrial Engineering and Engineering Management, IEEM 2008, pp. 1824-1829. doi: 10.1109/IEEM.2008.4738187.

Herrera, C., Belmokhtar-Berraf, S., Thomas, A. And Parada, V. (2015) 'A reactive decision-making approach to reduce instability in a master production schedule', International Journal of Production Research. Taylor \& Francis, 7543(September), pp. 1-11. doi: 10.1080/00207543.2015.1078516.

Hewitt, D., Sprague, K., Yearout, R., Lisnerski, D. and Sparks, C. (1992) 'The effects of unequal relearning rates on estimating forgetting parameters associated with performance curves', International Journal of Industrial Ergonomics, 10(3), pp. 217-224. doi: http://dx.doi.org/10.1016/0169-8141(92)90035-X.

ISO 22400 (2014) 'BSI Standards Publication Automation systems and integration - Key performance indicators ( KPIs) for manufacturing operations management Part 1: Overview, concepts and terminology'.

Ivanova, D., Batchkova, I., Panjaitan, S., Wagner, F. and Frey, G. (2009) 'Combining IEC 61499 and ISA S88 for batch control', IFAC Proceedings Volumes (IFAC-PapersOnline), 13(PART 1), pp. 187-192. doi: 10.3182/20090603-3-RU-2001.0189.

Jaber, M. Y., Kher, H. V. and Davis, D. J. (2003) 'Countering forgetting through training and deployment', International Journal of Production Economics, 85(1), pp. 33-46. doi: 10.1016/S0925-5273(03)00084-7.

Jiang, P., Ding, K. and Leng, J. (2016) 'Towards a cyber-physical-social-connected and service-oriented manufacturing paradigm: Social Manufacturing', Manufacturing Letters. Society of Manufacturing Engineers (SME), 7, pp. 15-21. doi: 10.1016/j.mfglet.2015.12.002.

Joung, C. B., Carrell, J., Sarkar, P. and Feng, S. C. (2013) 'Categorization of Indicators for Sustainable Manufacturing'. Ecological indicators, 24, pp. 1-19. 
Kagermann, P. D. H., Wahlster, P. D. W. and Helbig, D. J. (2013) Recommendations for implementing the strategic initiative INDUSTRIE 4.0.

Kang, H. S., Lee, J. Y., Choi, S., Kim, B. H. and Noh, R. (2016) 'Smart manufacturing: Past research, present findings, and future directions'. International Journal of Precision Engineering and manufacturing-green technology, 3(1), pp. 111-128.

Kim, M. C., Kim, C. O., Hong, S. R. and Kwon, I. H. (2008) 'Forward-backward analysis of RFID-enabled supply chain using fuzzy cognitive map and genetic algorithm', Expert Systems with Applications, 35(3), pp. 1166-1176. doi: 10.1016/j.eswa.2007.08.015.

Kim, Y. Y. and Oh, S. (2015) 'What makes smart work successful? overcoming the constraints of time geography', Proceedings of the Annual Hawaii International Conference on System Sciences, 2015March, pp. 1038-1047. doi: 10.1109/HICSS.2015.128.

Konopka, J. and Trybula, W. (1996) 'Overall equipment effectiveness (OEE) and cost measurement $\backslash n$ [semiconductor manufacturing]', Nineteenth IEEE/CPMT International Electronics Manufacturing Technology Symposium, (512), pp. 137-140. doi: 10.1109/IEMT.1996.559707.

Koste, L. L., \& Malhotra, M. K. (1999). A theoretical framework for analyzing the dimensions of manufacturing flexibility. Journal of Operations Management, 18(1), 75-93.

Kulik, J. A. and Fletcher, J. D. (2015) 'Effectiveness of Intelligent Tutoring Systems', 37, pp. 1-37. doi: 10.3102/0034654315581420.

Kulkarni, A., Payne, J. and Mistretta, P. (2015) 'Integrating SCADA, Load Shedding, and High-Speed Controls on an Ethernet Network at a North American Refinery', IEEE Transactions on Industry Applications, 51(2), pp. 1360-1368. doi: 10.1109/TIA.2014.2365366.

Lambert, S. J. (2008) 'Passing the buck: Labor flexibility practices that transfer risk onto hourly workers', Human Relations, 61(9), pp. 1203-1227. Available at: http://hum.sagepub.com/content/61/9/1203.abstract?rss=1 (Accessed: 8 June 2016).

Lanz, M., Majuri, M. and Tuokko, R. (2013) 'Information Flows in Future Advanced Manufacturing Ecosystems', Advances in Production Management Systems: Sustainable Production and Service Supply Chains, Pt 1, 414, pp. 70-77.

Longo, F., Nicoletti, L., \& Padovano, A. (2017). Smart operators in industry 4.0: A human-centered approach to enhance operators' capabilities and competencies within the new smart factory context. Computers \& Industrial Engineering, 113, 144-159.

Lowell Center for Sustainable Production (1998) Sustainable Production: A Working Definition. Informal Meeting of the Committee Members. Available at: https://www.uml.edu/Research/LowellCenter/About/Sustainable-Production-Defined.aspx

Lee, E. A. (2008) 'Cyber physical systems: Design challenges', Object Oriented Real-Time Distributed Computing (ISORC), 11th IEEE International Symposium on, pp. 363-369. doi: 10.1109/ISORC.2008.25.

Lee, E. A. (2015) 'The past, present and future of cyber-physical systems: A focus on models', Sensors (Switzerland), 15(3), pp. 4837-4869. doi: 10.3390/s150304837. 
Lee, H. G., Shin, B. and Higa, K. (2007) 'Telework vs. central work: A comparative view of knowledge accessibility', Decision Support Systems, 43(3), pp. 687-700. doi: 10.1016/j.dss.2006.11.007.

Lee, J., Bagheri, B. and Kao, H.A. (2014) 'Recent Advances and Trends of Cyber-Physical Systems and Big Data Analytics in Industrial Informatics', Int. Conference on Industrial Informatics (INDIN) 2014, (November 2015). doi: 10.13140/2.1.1464.1920.

Lee, J., Bagheri, B. and Kao, H. A. (2014) 'A Cyber-Physical Systems architecture for Industry 4.0-based manufacturing systems', Manufacturing Letters, 3(DECEMBER), pp. 18-23. doi: 10.1016/j.mfglet.2014.12.001.

Lewis, M. A. (2003) 'Cause, consequence and control: towards a theoretical and practical model of operational risk', Journal of Operations Management 205-224, 21(2), pp. 205-224.

Lin, Y.-H., Shie, J.-R. and Tsai, C.-H. (2009) 'Using an artificial neural network prediction model to optimize work-in-process inventory level for wafer fabrication', Expert Systems with Applications. Elsevier Ltd, 36(2), pp. 3421-3427. doi: 10.1016/j.eswa.2008.02.009.

Lin, Y. H. and Lee, C. E. (2001) 'Total standard WIP estimation method for wafer fabrication', European Journal of Operational Research, 131(1), pp. 78-94. doi: 10.1016/S0377-2217(99)00446-4.

Longoni, A., and Cagliano, R. (2015),'Environmental and social sustainability priorities', International Journal of Operations \& Production Management, Vol. 35 Iss 2 pp. 216 - 245

Longoni, A., Golini, R., and Cagliano, R. (2014). 'The role of New Forms of Work Organization in developing sustainability strategies in operations'. International Journal of Production Economics, 147, 147-160.

Malhotra, Y. (2001) 'Expert systems for knowledge management: Crossing the chasm between information processing and sense making', Expert Systems with Applications, 20(1), pp. 7-16. doi: 10.1016/S0957-4174(00)00045-2.

Mattsson, S., Karlsson, M., Fast-Berglund, Å., \& Hansson, I. (2014). Managing production complexity by empowering workers: six cases. Procedia CIRP, 17, 212-217.

Mavrikios, D., Papakostas, N., Mourtzis, D. and Chryssolouris, G. (2013) 'On industrial learning and training for the factories of the future: A conceptual, cognitive and technology framework', Journal of Intelligent Manufacturing, 24(3), pp. 473-485. doi: 10.1007/s10845-011-0590-9.

May, G., Barletta, I., Stahl, B. and Taisch, M. (2015) 'Energy management in production: A novel method to develop key performance indicators for improving energy efficiency', Applied Energy, 149, pp. 46-61. doi: 10.1016/j.apenergy.2015.03.065.

May, G., Taisch, M., Bettoni, A., Maghazei, O., Matarazzo, A. and Stahl, B. (2015) 'A New Human-centric Factory Model', Procedia CIRP. Elsevier B.V., 26, pp. 103-108. doi: 10.1016/j.procir.2014.07.112.

Meshkati, N., Hancock, P. A., Rahimi, M., \& Dawes, S. M. (1995). Techniques in mental workload assessment. In J. R. Wilson \& E. N. Corlett (Eds.), Evaluation of human work: A practical ergonomics methodology (pp. 749-782). Philadelphia: Taylor \& Francis.

MIL-STD-882 System Safety Program for Systems and Associated Subsystems and Equipments (2000). Available at: www.system-safety.org/Documents/MIL-STD-882D.pdf 
El Mola, K. G. and Parsaei, H. (2010) 'Dimensions and measures of manufacturing performance measurement', 40th International Conference on Computers and Industrial Engineering: Soft Computing Techniques for Advanced Manufacturing and Service Systems, CIE40 2010, (966). doi: 10.1109/ICCIE.2010.5668236.

Monostori, L. (2014) 'Cyber-physical production systems: Roots, expectations and R\&D challenges', Procedia CIRP, 17, pp. 9-13. doi: 10.1016/j.procir.2014.03.115.

Moraes, E. C., Lepikson, H. A., \& Colombo, A. W. (2015). Developing Interfaces Based on Services to the Cloud Manufacturing: Plug and Produce. In Industrial Engineering, Management Science and Applications 2015 (pp. 821-831). Springer, Berlin, Heidelberg.

Muller, C., Valle, M., Armengaud, E. and Tengg, A. (2011) 'A generic framework for failure modes and effects analysis of automotive networks', 2011 9th IEEE International Conference on Industrial Informatics, pp. 293-298. doi: 10.1109/INDIN.2011.6034891.

Neely, A., Gregory, M., and Platts, K. (1995). 'Performance measurement system design: a literature review and research agenda'. International Journal of Operations \& Production Management, 15(4), 80116.

Neves, P., Ribeiro, L., Dias-ferreira, J., Onori, M. and Barata, J. (2014) 'Exploring reconfiguration alternatives in Self- Organising Evolvable Production Systems through Simulation', 2014 12th IEEE International Conference on Industrial Informatics (INDIN), pp. 511-518. doi: 10.1109/INDIN.2014.6945566.

Ning, H., Liu, H., Ma, J., Yang, L. T. and Huang, R. (2015) 'Cybermatics: Cyber-physical-social-thinking hyperspace based science and technology', Future Generation Computer Systems. Elsevier B.V., 56, pp. 504-522. doi: 10.1016/j.future.2015.07.012.

National Institute of Standards and Technology (NIST) (2011). 'Sustainable Manufacturing Indicator Repository (SMIR)'. Available at: https://www.nist.gov/services-resources/software/sustainablemanufacturing-indicator-repository-smir

Parasuraman, R. and Riley, V. (1997) 'Humans and Automation: Use, Misuse, Disuse, Abuse', Human Factors: The Journal of the Human Factors and Ergonomics Society, 39(2), pp. 230-253. Available at: http://hfs.sagepub.com/content/39/2/230.short?rss=1\&ssource=mfc (Accessed: 27 May 2016).

Parasuraman, R., Sheridan, T. B. and Wickens, C. D. (2000) 'A model for types and levels of human interaction with automation.', IEEE transactions on systems, man, and cybernetics. Part A, Systems and humans: a publication of the IEEE Systems, Man, and Cybernetics Society, 30(3), pp. 286-97. doi: $10.1109 / 3468.844354$.

Parry, G. W., \& Winter, P. W. (1981). Characterization and evaluation of uncertainty in probabilistic risk analysis. Nuclear Safety;(United States), 22(1).

Peruzzini, M., \& Pellicciari, M. (2017). User experience evaluation model for sustainable manufacturing. International Journal of Computer Integrated Manufacturing, 1-19.

Pinzone, M., Fantini, P., Fiasché, M., and Taisch, M. (2016). A Multi-horizon, Multi-objective Training Planner: Building the Skills for Manufacturing. In Advances in Neural Networks (pp. 517-526). Springer International Publishing. 
Pirvu, B. C., Zamfirescu, C. B. and Gorecky, D. (2014) 'Engineering insights from an anthropocentric cyber-physical system: A case study for an assembly station', Mechatronics, 34, pp. 147-159. doi: 10.1016/j.mechatronics.2015.08.010.

Pretorius, A. and Cilliers, P. J. (2007) 'Development of a mental workload index: a systems approach.', Ergonomics, 50(9), pp. 1503-15.

Quagini, L., Tonchia S., (2010) Performance Measurement. Springer, Berlin, Heidelberg

Qin, J., Liu, Y., \& Grosvenor, R. (2016). A categorical framework of manufacturing for industry 4.0 and beyond. Procedia CIRP, 52, 173-178.

Raddon, a. and Grigsby, B. (1997) 'Throughput time forecasting model', 1997 IEEE/SEMI Advanced Semiconductor Manufacturing Conference and Workshop ASMC 97 Proceedings, pp. 430-433. doi: 10.1109/ASMC.1997.630775.

Rajak, S. and Vinodh, S. (2015) 'Application of fuzzy logic for social sustainability performance evaluation: a case study of an Indian automotive component manufacturing organization', Journal of Cleaner Production. Elsevier Ltd, 108, pp. 1184-1192. doi: 10.1016/j.jclepro.2015.05.070.

Ramos, C., Frasson, C. and Ramachandran, S. (2009) 'Introduction to the Special Issue on Real World Applications of Intelligent Tutoring Systems', IEEE Transactions on Learning Technologies, 2(2), pp. 6263. doi: 10.1109/TLT.2009.26.

Rastegarmoghadam, M. and Ziarati, K. (2016) 'Improved modeling of intelligent tutoring systems using ant colony optimization', Education and Information Technologies, (2). doi: 10.1007/s10639-016-9472-2.

Ribeiro, L., Rocha, A., Veiga, A. and Barata, J. (2015) 'Collaborative routing of products using a selforganizing mechatronic agent framework-A simulation study', Computers in Industry, 68, pp. 27-39. doi: 10.1016/j.compind.2014.12.003.

Richter, G., Bode, S. \& Köper, B. (2014). Demographic Changes in the Working World. Available at: http://www.baua.de/en/Publications/Focus/article30.pdf?_blob=publicationFile\&v=4

Romero, D. and Noran, O. (2015) 'Green virtual enterprises and their breeding environments: Engineering their sustainability as systems of systems for the circular economy', IFAC Proceedings Volumes (IFAC-PapersOnline). Elsevier Ltd., 48(3), pp. 2258-2265. doi: 10.1016/j.ifacol.2015.06.424.

Romero, D., Bernus, P., Noran, O., Stahre, J., \& Fast-Berglund, Å. (2016). The Operator 4.0: Human Cyber-Physical Systems \& Adaptive Automation towards Human-Automation Symbiosis Work Systems. In IFIP International Conference on Advances in Production Management Systems (pp. 677-686). Springer, Cham.

Romero, D., Noran, O., Stahre, J., Bernus, P. and Fasth-Berglund, A. (2015) 'Towards a Human-Centred Reference Architecture for Next Generation Balanced Automation Systems: Human-Automation Symbiosis', (March 2016).

Romero, D., Rabelo, R. J., Hincapie, M. and Molina, A. (2009) 'Next Generation Manufacturing Systems and the Virtual Enterprise', (June), pp. 634-641. doi: 10.3182/20090603-3-RU-2001.00105.

Rose, A. M. (1989) Acquisition and retention of skills, in: Application of Human Performance Models to System Design. 
Rosu, M., Doicin, C., Soković, M. and Kopač, J. (2008) 'Quality and cost in production management process', Strojniski Vestnik/Journal of Mechanical Engineering, 54(3), pp. 207-2018.

Sato, J. (2014) 'Capturing Benefits of M2M in Manufacturing', Hitachi Review, 63(1), pp. 25-29.

Sauter, T., Soucek, S., Kastner, W. and Dietrich, D. (2011) 'The Evolution of Factory and Building Automation', IEEE Industrial Electronic Magazine.

Schütte, M. (2009). Methods for measuring mental stress and strain. Industrial engineering and ergonomics, 395-411.

sCorPiuS (2016) sCorPiuS: European Roadmap for Cyber-Physical Systems in Manufacturing. Gap Analysis on Research and Innovation and Vision White Paper. D2.1.

Searcy, C., Dixon, S. M. and Patrick Neumann, W. (2016) 'The use of work environment performance indicators in corporate social responsibility reporting', Journal of Cleaner Production, 112, pp. 29072921. doi: 10.1016/j.jclepro.2015.10.081.

Sethi, A. K., \& Sethi, S. P. (1990). Flexibility in manufacturing: a survey. International journal of flexible manufacturing systems, 2(4), 289-328.

Seuring, S., and Gold, S. (2012). 'Conducting content-analysis based literature reviews in supply chain management'. Supply Chain Management: An International Journal, 17(5), 544-555.

Shen, W., Hao, Q., Yoon, H. J. and Norrie, D. H. (2006) 'Applications of agent-based systems in intelligent manufacturing: An updated review', Advanced Engineering Informatics, 20(4), pp. 415-431. doi: 10.1016/j.aei.2006.05.004.

Sheridan, T. and Parasuraman, R. (2005) 'Human-automation interaction', Reviews of human factors and Ergonomics, pp. 89-129. Available at: http://rev.sagepub.com/content/1/1/89.short.

Skowroński, A., \& Werewka, J. (2015, September). A quality attributes approach to defining reactive systems solution applied to cloud of sensors. In Computer Science and Information Systems (FedCSIS), 2015 Federated Conference on (pp. 789-795). IEEE.

Sperling, L., Dahlman, S., Kilbom and Kadefors, R. (1993) 'A cube model for the classification of work with hand tools and formulation of functional requirements', Applied Ergonomics, 24(3), pp. 212-220.

Srivastava, M., Abdelzaher, T. and Szymanski, B. (2012) 'Human-centric sensing', Philosophical Transactions of the Royal Society A: Mathematical, Physical and Engineering Sciences, 370(1958), pp. 176-197. doi: 10.1098/rsta.2011.0244.

Stecke, K. E., \& Raman, N. (1995). FMS planning decisions, operating flexibilities, and system performance. IEEE Transactions on Engineering Management, 42(1), 82-90.

Stottler, R. and Panichas, S. (2006) 'A New Generation of Tactical Action Officer Intelligent Tutoring System (ITS)', The Interservice/Industry Training, Simulation \& Education Conference (I/ITSEC), 2006(1), pp. 1-10. Available at: http://ntsa.metapress.com/index/7l8f7t1bk1x5htm0.pdf.

Susto, G. A., Schirru, A., Pampuri, S., McLoone, S. and Beghi, A. (2015) 'Machine learning for predictive maintenance: A multiple classifier approach', IEEE Transactions on Industrial Informatics, 11(3), pp. 812820. doi: 10.1109/TII.2014.2349359. 
Sutherland, J. W., Richter, J. S., Hutchins, M. J., Dornfeld, D., Dzombak, R., Mangold, J., Robinson. S., Hauschild, M. Z., Bonoue, A., Schönsleben, P., Friemann, F. (2016). The role of manufacturing in affecting the social dimension of sustainability. CIRP Annals-Manufacturing Technology, 65(2), 689-712.

Taghavi, N., Adams, C., \& Berlin, C. (2014). Social sustainability KPIs in operations management: a gap between the reactive and the proactive stance. In Swedish Production Symposium 2014, SPS14.

Tan, L. P. and Wong, K. Y. (2015) 'Linkage between knowledge management and manufacturing performance: a structural equation modeling approach', Journal of Knowledge Management, 19(4), pp. 814-835. doi: 10.1108/JKM-11-2014-0487.

Taylor, J. R. (1994) 'Risk Analysis for process plant, pipelines and transport', E\&FN Spon, UK.

Terzi, S. and Cavalieri, S. (2004) 'Proposal of a performance measurement system for the evaluation of scheduling solutions', Conference Proceedings - IEEE International Conference on Systems, Man and Cybernetics, 4, pp. 3827-3832. doi: 10.1109/ICSMC.2004.1400941.

Ullrich, J., Voyiatzis, A. G., \& Weippl, E. R. (2016). Secure cyber-physical production systems: Solid steps towards realization. In Cyber-Physical Production Systems (CPPS), 2016 1st International Workshop on (pp. 1-4). IEEE.

Vale, Z. A., Morais, H., Silva, M. and Ramos, C. (2009) 'Towards a future SCADA', 2009 IEEE Power and Energy Society General Meeting, PES '09, pp. 1-7. doi: 10.1109/PES.2009.5275561.

Wetzel, J., VanLehn, K., Butler, D., Chaudhari, P., Desai, A., Feng, J., Grover, S., Joiner, R., Kong-Sivert, M., Patade, V., Samala, R., Tiwari, M. and van de Sande, B. (2016) 'The design and development of the dragoon intelligent tutoring system for model construction: lessons learned', Interactive Learning Environments, 4820(April), pp. 1-21. doi: 10.1080/10494820.2015.1131167.

Wilson, G. F. and Russell, C. A. (2003) 'Real-Time Assessment of Mental Workload Using Psychophysiological Measures and Artificial Neural Networks', Human Factors: The Journal of the Human Factors and Ergonomics Society, 45(4), pp. 635-643.

Wilson, G. F. and Russell, C. A. (2007) 'Performance Enhancement in a UAV Task Using Psychophysiologically determined Adaptive Aiding'. Air Force Research Laboratory, Wright Patterson Air Force Base, Ohio, pp. 1005-1018.

Winroth, M., Almström, P. and Andersson, C. (2012) 'Sustainable indicators at factory level - A framework for practical assessment', 62nd IIE Annual Conference and Expo 2012, 21, pp. 490-503.

Winroth, M., Winroth, M., Almström, P., Almström, P., Andersson, C., and Andersson, C. (2016). 'Sustainable production indicators at factory level'. Journal of Manufacturing Technology Management, 27(6), 842-873.

Zaeh, M. F. and Ostgathe, M. (2009) 'A multi-agent-supported, product-based production control', 2009 IEEE International Conference on Control and Automation, ICCA 2009, pp. 2376-2383. doi: 10.1109/ICCA.2009.5410562.

Zamfirescu, C.-B., Pirvu, B.-C., Gorecky, D. and Chakravarthy, H. (2014) 'Human-centred Assembly: A Case Study for an Anthropocentric Cyber-physical System', Procedia Technology, 15, pp. 90-98. doi: 10.1016/j.protcy.2014.09.038. 
Zhang, W. J. and Van Luttervelt, C. A. (2011) 'Toward a resilient manufacturing system', CIRP Annals Manufacturing Technology, 60(1), pp. 469-472. doi: 10.1016/j.cirp.2011.03.041.

Zhang, Y., Zhang, G., Wang, J., Sun, S., Si, S. and Yang, T. (2014) 'Real-time information capturing and integration framework of the internet of manufacturing things', International Journal of Computer Integrated Manufacturing, 3052(December), pp. 1-12. doi: 10.1080/0951192X.2014.900874.

\section{Highlights}

- Six Functionalities of a Human-centric CPPS are illustrated

- Three levels of analysis of CPPS are defined

- The CyFL Matrix aims to identify and organise performances in Human-centric CPPS

- CyFL Matrix is a tool for companies interested in Human-centric CPPS' performances 


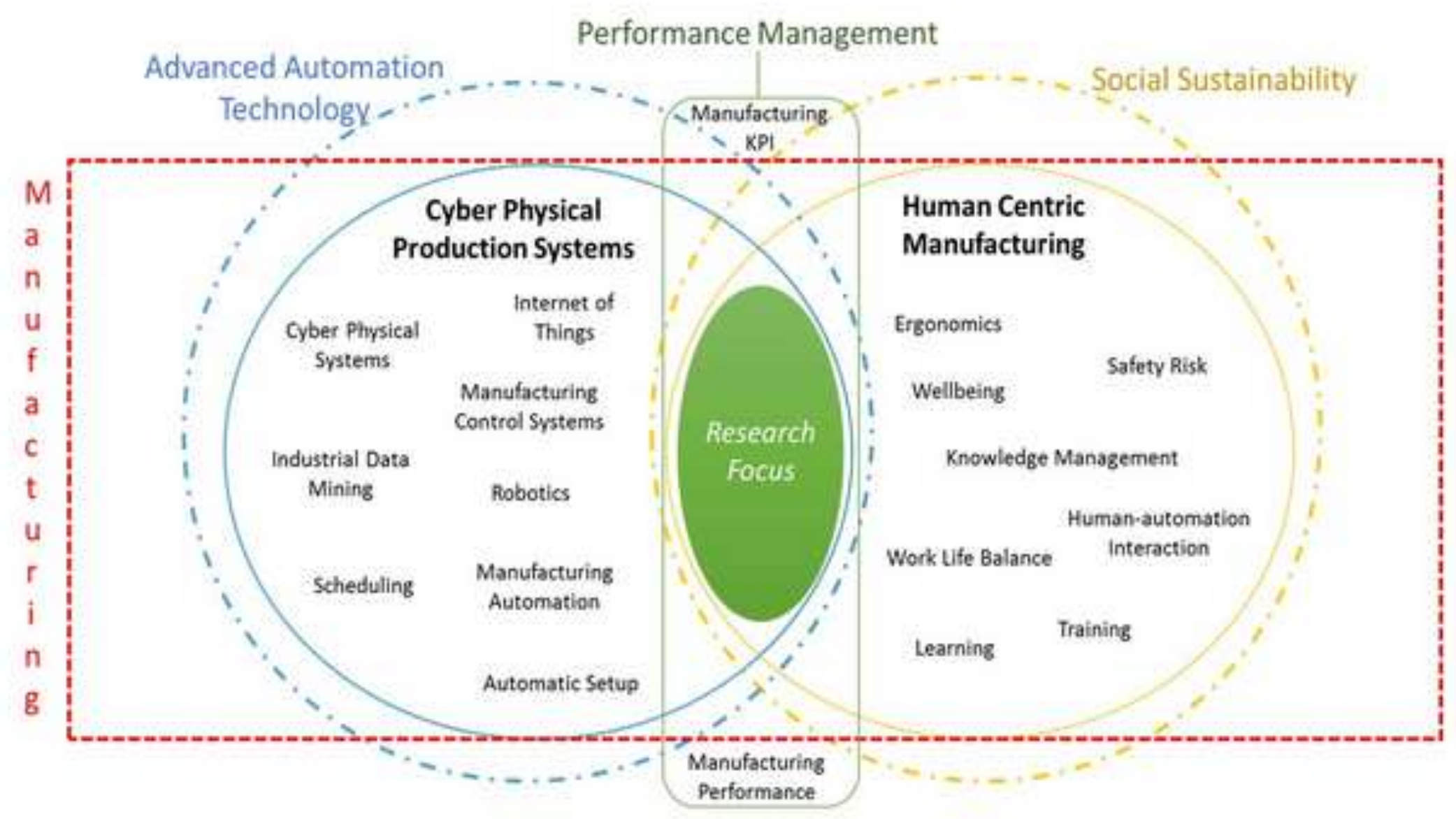




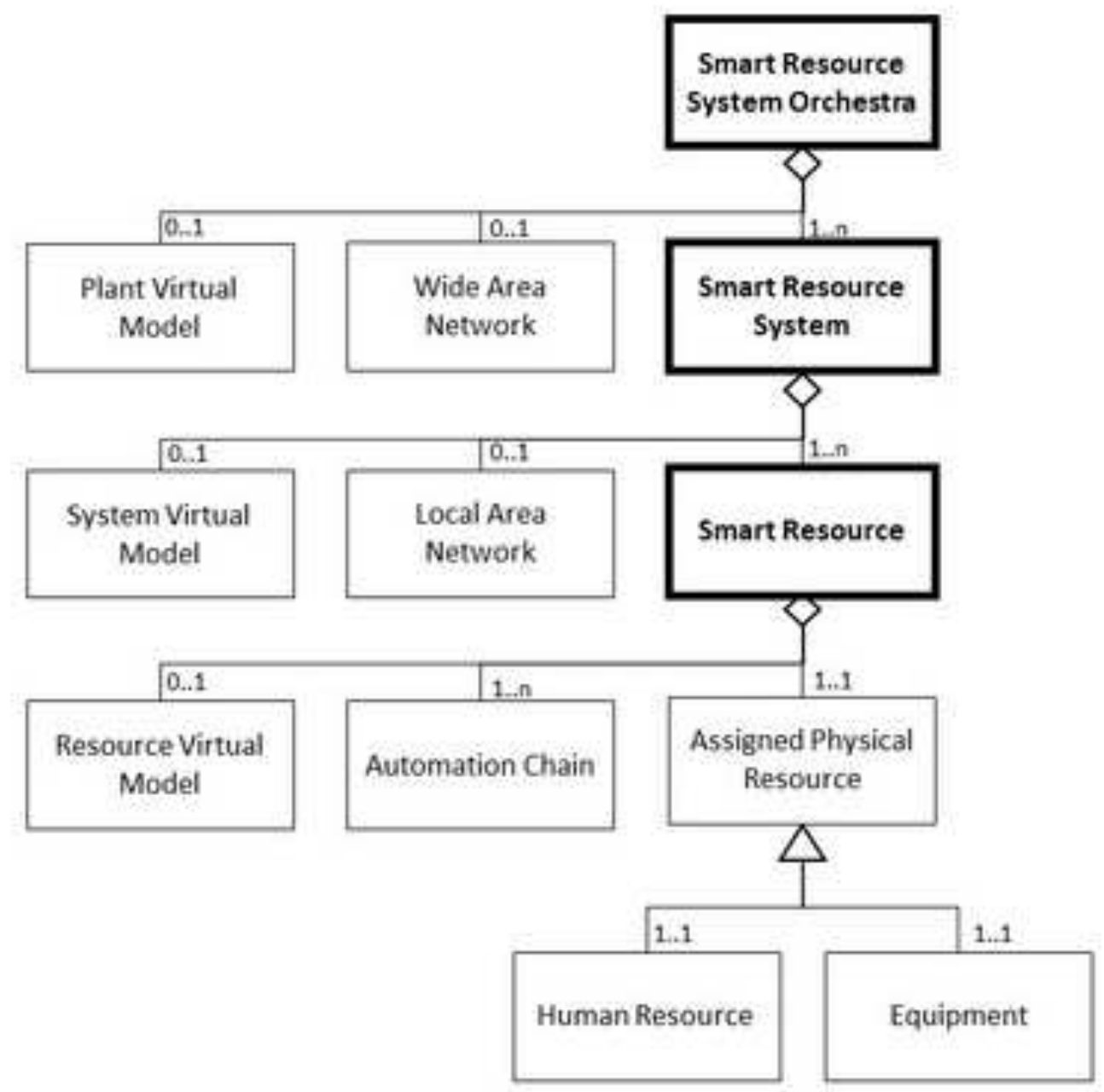




\begin{tabular}{|c|c|c|c|}
\hline & $\begin{array}{c}\text { Smart } \\
\text { Resource } \\
\text { [\$R] }\end{array}$ & * $\begin{array}{c}\text { Smart } \\
\text { Resource System } \\
\text { [SAS] }\end{array}$ & $\begin{array}{l}\text { Smart Resource } \\
\text { System Orchestra } \\
\text { (SRSO) }\end{array}$ \\
\hline If Silent & $\begin{array}{l}\text { Optraters Trainingleve! } \\
\text { Operater's Learning } \\
\text { [Spetd snd Retenteded }\end{array}$ & $\begin{array}{l}\text { Lobour flexibilsy (Proceess Celi) } \\
\text { Human Etrot ineidence }\end{array}$ & 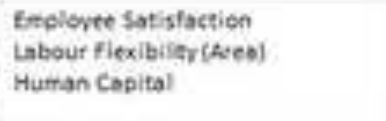 \\
\hline $\begin{array}{l}\text { Knowledge } \\
\text { eo Manager (KM) }\end{array}$ & 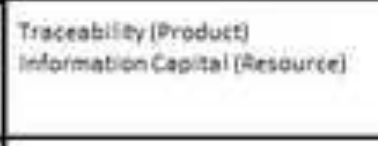 & 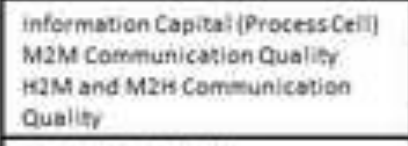 & $\begin{array}{l}\text { Plant Accessibitity } \\
\text { Information Capitas (Area) } \\
\text { Innovation \& Knowledet }\end{array}$ \\
\hline $\begin{array}{l}\text { gopso Resource } \\
\text { Integrator (Rl) }\end{array}$ & Product slentibitty & 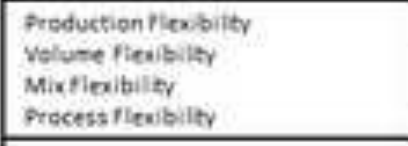 & 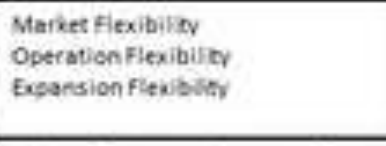 \\
\hline CareGiver (cG) & $\begin{array}{l}\text { Wellbeing } \\
\text { - Physicastrain } \\
\text { - Psvenolosical strain }\end{array}$ & $\begin{array}{l}\text { Humsun Error incidence } \\
\text { (Failes Delence) }\end{array}$ & $\begin{array}{l}\text { Adoptabisity to a diverse vorkforce } \\
\text { antractiveness of the workplace } \\
\text { internal Quaglity }\end{array}$ \\
\hline $\begin{array}{l}\text { Risk Manager } \\
\text { (RM) }\end{array}$ & 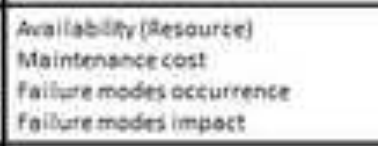 & 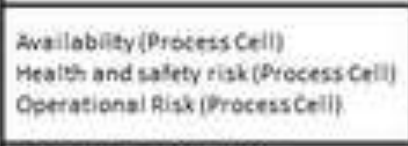 & $\begin{array}{l}\text { Resilience of Productiso Sustem } \\
\text { Operatipnai Risk } \\
\text { Health \& Safety kisk }\end{array}$ \\
\hline $\begin{array}{l}\text { Flow Master } \\
\text { (FM) }\end{array}$ & $\begin{array}{l}\text { Resovece Efficiency (thime) } \\
\text { Eternat Quasitr(Task Euecution, } \\
\text { Process Output). }\end{array}$ & 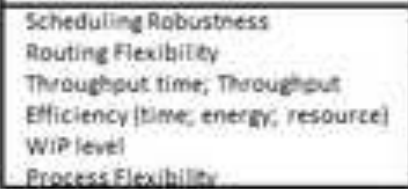 & $\begin{array}{l}\text { Inventoory costs } \\
\text { Frosen Period } \\
\text { cost Eticiency } \\
\text { Enternaci iualisy } \\
\text { Production tead time }\end{array}$ \\
\hline
\end{tabular}




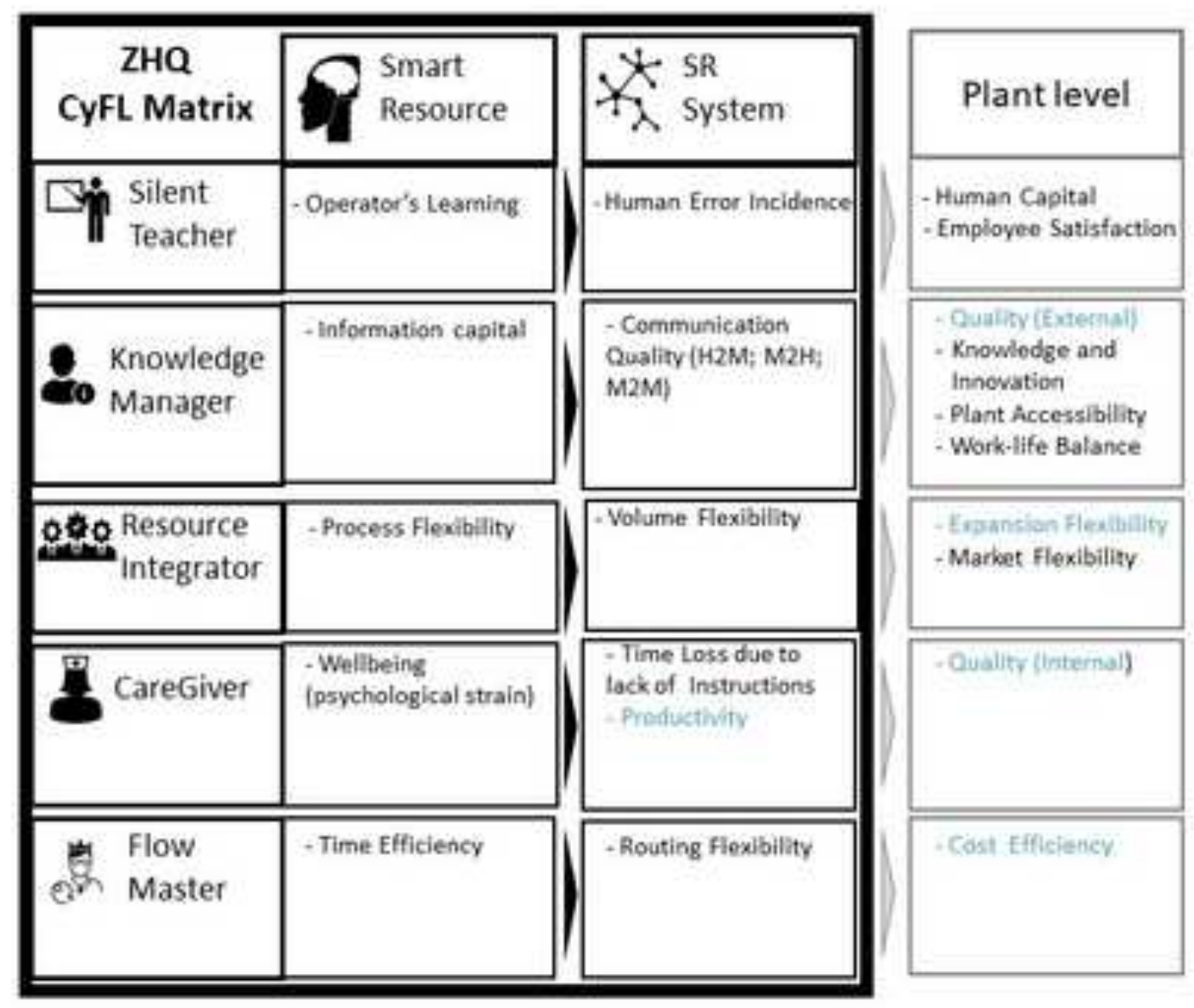

